\title{
Métodos de avaliação da implantação da manufatura enxuta: Uma revisão da literatura e classificação
}

\author{
Assessment methods of lean manufacturing: Literature \\ review and classification
}

\author{
Olga Maria Formigoni Carvalho Walter ${ }^{1}$ \\ Dalvio Ferrari Tubino ${ }^{1}$
}

\begin{abstract}
Resumo: Apesar da ampla literatura existente sobre Manufatura Enxuta (ME), pouco esforço tem sido dedicado a sintetizar o estado da arte sobre métodos que avaliam sua implantação. Nesse sentido, este artigo tem como objetivo apresentar uma revisão da literatura sobre métodos científicos de avaliação da implantação da ME, buscando identificar suas principais características. Foram identificados 48 artigos relacionados ao tema, no período de 1996 a agosto de 2012. Depois da revisão, as publicações foram classificadas, utilizando os seguintes parâmetros de caracterização: tipo de abordagem metodológica; foco de avaliação; forma de apresentação do diagnóstico; dinâmica de aplicação do diagnóstico de avaliação; práticas clássicas da ME avaliadas; entre outros parâmetros complementares. A principal contribuição desta pesquisa concentra-se em condensar em um único material, uma visão geral sobre os métodos de avaliação da ME para que pesquisadores e profissionais da área selecionem o método que melhor se adapte à realidade de determinada empresa, ou o que ofereça a melhor perspectiva de como se apresenta a implantação da ME.
\end{abstract}

Palavras-chave: Manufatura enxuta. Método de avaliação. Implantação. Revisão.

\begin{abstract}
Despite the extensive literature on Lean Manufacturing (LM), little effort has been made to synthetize the state-of-the-art methods used to assess LM implementation. Accordingly, this article aims to present a literature review on scientific assessment methods for LM to identify their main characteristics. Forty eight articles related to the topic published between 1996 and August 2012 were identified. These publications were then classified using the following characterization parameters: methodological approach, assessment focus, diagnostic process procedure; diagnostic assessment dynamics; and classic LM practices assessed among other complementary parameters. The main contribution of this research is to provide researchers and management professionals with a compiled account of LM assessment methods for easy identification of the most suitable method for the environment of a certain company or that which offers the best perspective on their own LM implementation status.
\end{abstract}

Keywords: Lean manufacturing. Assessment method. Implementation. Review.

\section{Introdução}

Diante da acelerada difusão da Manufatura Enxuta (ME) desde a década de 1980 (WHITE; PEARSON; WILSON, 1999), surgiu a necessidade de desenvolver meios para investigar o nível de maturidade de sua implantação. De fato, é grande a preocupação em como implantar a ME, porém avaliar o quão enxutas as empresas se apresentam, tem recebido menos atenção na literatura (WAN; CHEN, 2008; BHASIN, 2011).

Apesar de maneiras de como implantar a ME terem sido exaustivamente discutidas na literatura por mais de duas décadas, conforme atestam algumas publicações (IM; LEE, 1989; GUPTA; BRENNAN, 1995; AHLSTRÖM, 1998; WAFA; YASIN, 1998; CRUTE et al. 2003; ACHANGA et al., 2006; BLACK, 2007; MORIONES; PINTADO; CERIO, 2008; ANAND; KODALI, 2010; PUVANASVARAN et al.,
2010), implementações sem sucesso são comuns. E, embora a implantação enxuta continue nas empresas, ainda há preocupação sobre falhas nestes programas (SHAH; WARD, 2007; CHAKRAVORTY, 2010).

De acordo com Bhasin (2008), é necessário investigar estatisticamente quantas empresas obtiveram êxito na implantação da $\mathrm{ME}$, devido ao grande número de iniciativas sem sucesso. Conforme Bhasin e Burcher (2006), Bhasin (2008) e Sellitto, Borchardt e Pereira (2010), em torno de apenas $10 \%$ das empresas têm sido bem sucedidas na implementação da ME. Pay (2008) afirma que nos Estados Unidos mais de 70\% das indústrias implantam a ME como uma estratégia de melhoria, porém apenas $2 \%$ das empresas têm atingido plenamente seus objetivos e $74 \%$ delas admitem não estarem fazendo um bom progresso com

\footnotetext{
${ }^{1}$ Programa de Pós-graduação em Engenharia de Produção - PPGEP, Universidade Federal de Santa Catarina - UFSC, CP 476, CEP 88010-970, Florianópolis, SC, Brasil, e-mail: olgaformigoni@gmail.com; tubino@ deps.ufsc.br
}

Recebido em 6/12/2011 — Aceito em 23/9/2012

Suporte financeiro: CAPES. 
sua implantação. Segundo Pavnaskar, Gershenson e Jambekar (2003), tornar-se uma empresa enxuta não é tão fácil quanto parece e a aplicação errada de determinadas ferramentas podem resultar em desperdício adicional de recursos. Estudos de Taj (2005) também corroboram com esta informação, afirmando que a maioria das empresas desperdiça de $70 \%$ a $90 \%$ de seus recursos na implantação da ME, e até mesmo as empresas em melhores situações de implantação desperdiçam em torno de $30 \%$ de seus recursos.

Diante das declarações de que a ME nem sempre apresenta os resultados esperados, apesar das grandes possibilidades de melhorias de desempenho em muitos casos (MATSUI, 2007; SHAH; WARD, 2007; RAHMAN; LAOSIRIHONGTHONG; SOHAL, 2010), é imperativo que qualquer empresa seja capaz de avaliar o estado do progresso de sua implantação na busca de se tornar enxuta (BHASIN, 2011). De acordo com Shah e Ward (2007), estudos empíricos sobre ME estão em fase inicial de desenvolvimento e precisam de métodos confiáveis e válidos que garantam sua avaliação. O que vem de encontro com o que propõe Bhasin (2011) quando afirma que são escassos os parâmetros confiáveis para julgar se o nível da implementação enxuta das empresas está progredindo.

Nesse contexto de incertezas quanto ao estado da implantação da ME é que surgiu a motivação desta pesquisa, uma vez que não foi encontrado na literatura um estudo completo abordando como está o andamento das pesquisas em termos de desenvolvimento de métodos de avaliação da ME. Assim, este artigo tem como objetivo preencher esta lacuna, apresentando uma revisão da literatura sobre métodos científicos de avaliação da ME, buscando identificar suas principais características, tendências e oportunidades de novos desdobramentos para pesquisas futuras.

Apesar dos métodos de avaliação da ME cobrirem vários aspectos críticos com relação a sua implantação, é difícil encontrar o que se encaixe perfeitamente em todas as empresas e em todos os sistemas produtivos (KUMAR; THOMAS, 2002; WAN; CHEN, 2008). Assim, acredita-se que, reunir estas informações em um único material, será útil para que pesquisadores e profissionais da área selecionem o método que melhor se adapte à realidade da empresa avaliada, ou o que ofereça a melhor perspectiva de como se apresenta a implantação da ME.

Este trabalho está estruturado da seguinte forma: na seção 2 , são detalhados os procedimentos metodológicos utilizados na condução desta pesquisa. $\mathrm{Na}$ terceira seção, são descritos os parâmetros para caracterização das publicações coletadas. Os métodos de avaliação da ME identificados na literatura são brevemente descritos na quarta seção. Na quinta seção, é apresentado o resultado da classificação dos artigos estudados de acordo com os parâmetros apresentados na seção 3. Finalmente, na seção 6, são expostas as conclusões e lacunas identificadas no tema pesquisado.

\section{Método de pesquisa}

Esta pesquisa caracteriza-se como um estudo exploratório por realizar uma revisão da literatura acerca de como está o desenvolvimento de métodos de avaliação da ME. É também considerado um estudo teórico-conceitual, no qual se realiza uma discussão dos métodos de avaliação da ME, selecionados por meio de pesquisa bibliográfica.

Justifica-se a utilização da pesquisa bibliográfica, pois uma das funções do presente trabalho é identificar, conhecer e acompanhar o desenvolvimento da pesquisa em determinada área do conhecimento. Além disso, as pesquisas bibliográficas possibilitam identificar o estado da arte e possíveis lacunas que podem existir, além de identificar oportunidades para novas contribuições no tema em estudo (MEREDITH, 1993; VILLAS; SOARES; RUSSO, 2008), apontando perspectivas para pesquisas futuras (NORONHA; FERREIRA, 2000).

A estrutura metodológica adotada na condução do levantamento bibliográfico é apresentada na Figura 1. O método diferencia-se em parte do proposto por Villas, Soares e Russo (2008) devido ao fato de que, assim como em outros trabalhos de revisão da literatura da área de engenharia de produção e gestão de operações (MARASCO, 2008; CARNEVALLI; MIGUEL, 2008; LAGE JÚNIOR; GODINHO FILHO, 2010), foram considerados apenas os artigos publicados em periódicos científicos, pois sua seleção e avaliação são mais criteriosas que as dos artigos de congressos e simpósios (CARNEVALLI; MIGUEL, 2008), além de serem considerados como pesquisas de mais alto nível, tanto para coleta de informações, quanto para divulgação de novas descobertas (NGAI et al., 2008).

$\mathrm{Na}$ fase inicial, para localizar as fontes bibliográficas adequadas ao desenvolvimento desta pesquisa, foram consultadas, entre as áreas do conhecimento, Engenharias e Multidisciplinar, as seguintes bases de dados, disponíveis nos periódicos da Coordenação de Aperfeiçoamento de Pessoal de Nível Superior (CAPES): ACM Digital Library, ACS Journals Search, Cambridge University Press, EBSCO, Emerald, Gale, HighWire Press, IEEE Xplore, ProQuest, Sage, SciELO, ScienceDirect (Elsevier), Scopus, SpringerLink (MetaPress) e Wilson. A utilização do portal CAPES é justificada devido a sua grande abrangência e facilidade de acesso para a comunidade científica brasileira a versões eletrônicas dos principais periódicos científicos (MEIRELLES; MACHADO, 2007).

$\mathrm{Na}$ segunda fase, para selecionar as publicações de interesse, foi pesquisado por meio do abstract, key words e title, sem restrição ao período de publicação, as seguintes palavras-chave, individuais e combinadas: 
lean, just in time, leanness, assessment, measure, measurement, performance, model, metric e index. Na sequência, procedeu-se à leitura e análise do title e abstract dos artigos encontrados, selecionando-se os que apresentavam relevância para os objetivos do trabalho. O critério de exclusão principal foi o de levar em conta apenas os trabalhos focados principalmente em avaliação da ME, desconsiderando da análise artigos que avaliam uma prática isolada da ME, tal como kanban ou Troca Rápida de Ferramentas; e artigos que avaliam a implantação da ME em aspectos isolados como os encontrados em algumas publicações, como, por exemplo: Fogarty (1992), Biazzo e Pannizzolo (2000), Haque e Moore (2004), Rawabdeh (2005), Swamidass (2007), Fazard, Mohamad e Hosseini (2008), Saurin, Marodin e Ribeiro (2011) e Arbos, Santos e Sánchez (2011).

Finalmente, a seleção de novos documentos identifica nas referências bibliográficas dos artigos selecionados na fase 2 novos métodos de avaliação da ME, a fim de inseri-los como novas referências, tornando a pesquisa bibliográfica mais robusta, tal como mostra a Figura 1.

\section{Parâmetros de caracterização dos artigos estudados}

Os parâmetros utilizados para identificar as principais características e o perfil dos trabalhos coletados são: abordagem metodológica; foco; forma de apresentação do diagnóstico; dinâmica de aplicação do diagnóstico de avaliação; e práticas da ME.

Além dos parâmetros previamente citados, verificou-se o país de origem do método, a quantidade de empresas e setor industrial em que o método foi aplicado. Também foi verificado se a publicação tem como base outro método de avaliação da ME publicado previamente, se apresenta o instrumento de coleta de dados completo utilizado para gerar o diagnóstico de avaliação da ME, e se possui suporte financeiro para condução da pesquisa.

A escolha destes parâmetros buscou sintetizar as principais características comuns dos artigos de modo a apresentar melhor perspectiva de cada método, tanto para pesquisadores que procuram desenvolver e aperfeiçoar as pesquisas na área, quanto para profissionais e especialistas em ME que buscam por um método de avaliação que melhor se adapte à realidade industrial em que atuam.

\subsection{Abordagem metodológica}

A abordagem metodológica trata do tipo de metodologia de pesquisa adotada no trabalho. Os tipos considerados nesta classificação são: teóricoconceitual, experimento, modelagem, simulação, survey, estudo de caso e pesquisa-ação. A escolha por estas metodologias justifica-se pelo fato de que, segundo Filippini (1997), Berto e Nakano (2000)

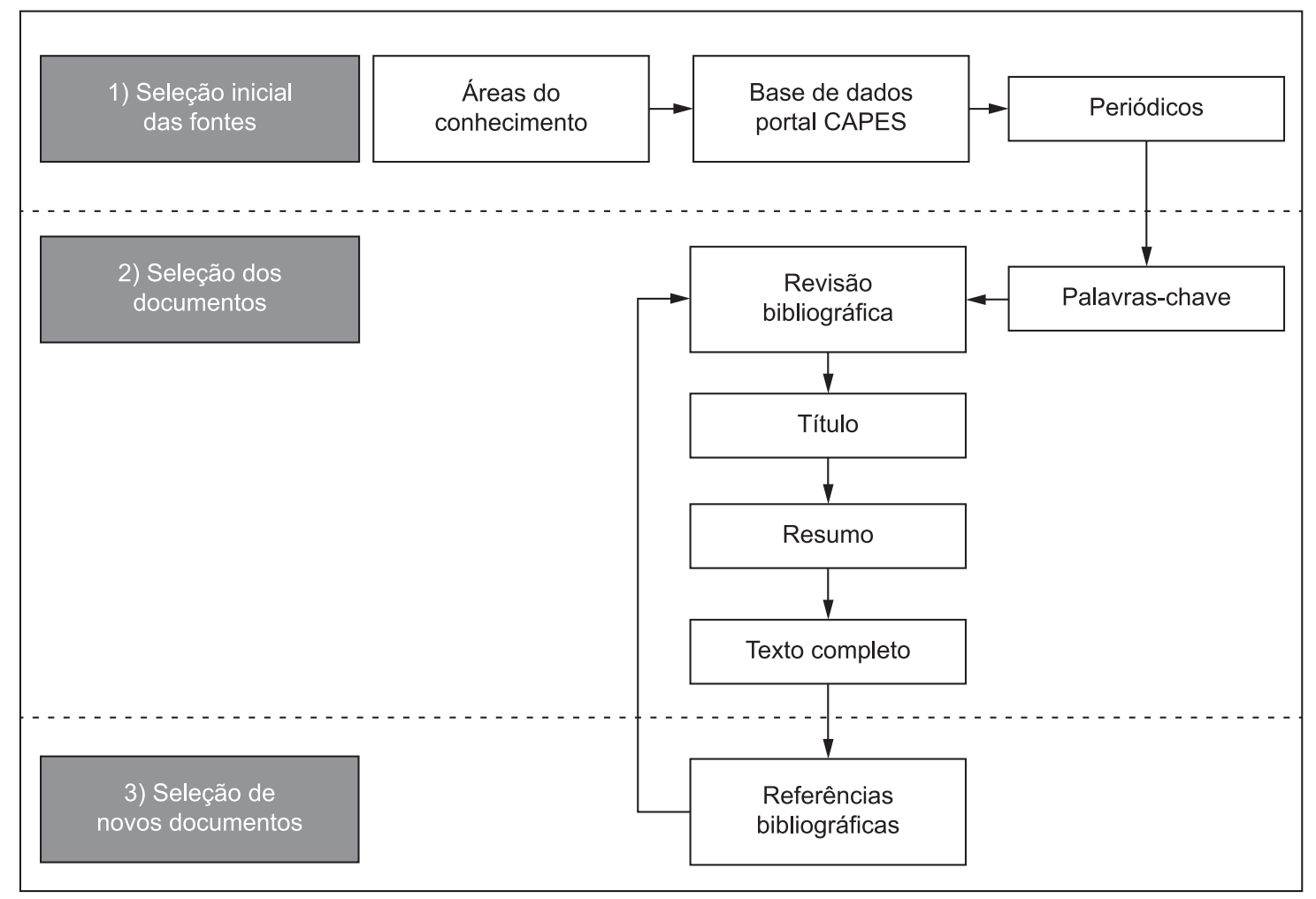

Figura 1. Estrutura metodológica da pesquisa bibliográfica. Fonte: Adaptado de Villas, Soares e Russo (2008). 
e Miguel (2007), essas abordagens são as mais utilizadas em pesquisas relacionadas à gestão da produção e operações.

\subsection{Foco}

Refere-se ao alcance de avaliação do método, considerando três possibilidades: "manufatura", "cadeia de suprimentos" e "empresa". A delimitação de uma abrangência além do chão de fábrica, origem e principal foco de atuação da ME, é necessária, pois os princípios da ME vêm sendo aplicados com êxito e expandindo-se nos mais diversos departamentos, levando a criar uma "Empresa Enxuta".

"Manufatura" considera métodos que são focados em avaliar a ME diretamente no chão de fábrica, seja pelas práticas utilizadas ou pelos princípios adotados.

Consideram-se métodos com foco na "cadeia de suprimentos" aqueles que apresentam alguma forma de interação e avaliação de aspectos ligados a fornecedores, bem como o seu desenvolvimento, além de métodos que se preocupam em avaliar aspectos logísticos, tais como entregas milk run e gerenciamento de centros de distribuição enxutos.

O foco "empresa" não se limita às atividades que ocorrem na função de produção. Está relacionado com atividades que vão desde desenvolvimento de produtos, compras, fabricação até a distribuição, por meio de princípios que caracterizam as diferentes áreas funcionais e a estratégia global para formar a empresa enxuta.

\subsection{Forma de apresentação do diagnóstico de avaliação}

Este parâmetro procura classificar como é apresentado o resultado final da aplicação do método de avaliação da ME: se predomina a forma qualitativa por meio de relatos descritivos das situações e práticas observadas ou se prevalece a forma quantitativa, com índice, escala ou alguma forma de arranjo numérico que apresente quão enxuta a empresa se encontra.

\subsection{Dinâmica de aplicação do diagnóstico}

Procura identificar a forma geral da dinâmica de aplicação do método com relação às pessoas, ou seja, se a aplicação do diagnóstico é direcionada ao nível operacional, tático ou estratégico.

O nível operacional compreende as pessoas cujas atividades estão diretamente envolvidas com a ME, tal como operadores de máquinas e analistas de processo, analistas de planejamento e controle da produção, analistas logísticos e administrativos. O tático inclui o nível de supervisão, como as pessoas responsáveis pela supervisão da produção, planejamento e controle da produção (PCP), compras, manutenção e logística.
Finalmente, o nível estratégico inclui a diretoria e presidência da empresa avaliada.

\subsection{Práticas da manufatura enxuta}

Este parâmetro está relacionado com as práticas da ME que o método selecionado avalia. A seleção de práticas típicas da ME ocorreu mediante criteriosa análise de referências clássicas relacionadas ao assunto, tal como: Womack e Jones (1992), Womack, Jones e Roos (1992), Takahashi e Osada (1993), Imai (1994), Shingo (1996a, b, 2000), Ohno (1997), Rother e Harris (2002), Rother e Shook (2003), Liker (2005) e Tubino (2007).

Para evitar duplicidade de práticas com o mesmo significado e unificar a codificação proposta, foram agrupadas práticas da $\mathrm{ME}$ que são encontradas na literatura com termos diferenciados, mas que possuem significado semelhante, tal como: nivelamento da produção e heijunka; flexibilidade da mão de obra e força de trabalho multifuncional; redução de setup e troca rápida de ferramentas; autonomação e jidoka.

\section{Métodos de avaliação da manufatura enxuta identificados na literatura}

Nesta seção, são apresentados os resultados da revisão de literatura coletada de acordo com a ordem cronológica de publicação.

Karlsson e Ahlström (1996) apresentam um método com nove princípios: eliminação de desperdícios, melhoria contínua, zero defeitos, Just in Time (JIT), puxar ao invés de empurrar, equipes multifuncionais, responsabilidades descentralizadas, funções integradas e sistemas de informação vertical. Cada princípio tem um conjunto de indicadores que avaliam a extensão pela qual é adotado, refletindo as mudanças com a implantação da ME.

A estrutura do método de avaliação de Sánchez e Pérez (2001) é uma lista de verificação composta por seis princípios desdobrados em trinta e seis indicadores. Os seis princípios utilizados no método são: eliminação das atividades que não agregam valor; melhoria contínua; equipes multifuncionais; produção e entrega JIT; integração de fornecedores; e sistema de informação flexível.

Goodson (2002) apresenta o Rapid Assessment Plant (RPA). Este método considera que, com uma visita rápida ao chão de fábrica de menos de 1 hora, é possível revelar se uma fábrica é realmente enxuta. Utiliza a taxa de RPA, uma ficha que apresenta 11 categorias para a avaliação da planta; e o questionário RPA, que dispõe de 20 perguntas para determinar se a planta usa ou não melhores práticas.

Kumar e Thomas (2002) apresentam um software para a empresa avaliar o nível de práticas enxutas 
em uso em suas instalações. Neste método, esforços foram voltados para incluir práticas verdes, a fim de mostrar como estas medidas favorecem a organização não só economizar dinheiro, mas também reduzir potenciais problemas ambientais.

Soriano-Meier e Forrester (2002) utilizam nove variáveis semelhantes às de Karlsson e Ahlström (1996) para examinar a adoção dos princípios enxutos nas empresas e o comprometimento da gerência com a ME. Por meio destas variáveis, as empresas são classificadas como enxutas ou empresas em transição.

O método Lean Enterprise Self-Assessment Tool (NIGHTINGALE; MIZE, 2002) é dividido em três seções de avaliação e é composto por 54 práticas enxutas. Na seção I (Transformação e Liderança Enxuta), o foco está sobre as práticas enxutas e processos que são desenvolvidos e mantidos no mais alto nível para orientar as atividades da organização. A Seção II (Ciclo de Vida de Processos) aborda o nível de implementação enxuta nos processos. Já a Seção III (Possibilitar a Infraestrutura) apoia a execução da seção I e II, dando apoio a outras unidades organizacionais a quem eles servem como clientes internos.

Com a finalidade de avaliar a ME e identificar os fatores que determinam sua taxa de adoção, Kojima e Kaplinski (2004) desenvolveram um indicador constituído de 3 índices, considerados polos relacionados com a mudança: flexibilidade e logística; qualidade; e melhoria contínua. O indicador é calculado agregando a média das pontuações em cada um dos três índices, classificando a empresa como forte, média ou fraca.

Cardoza e Carpinetti (2005) reúnem e discutem um conjunto de indicadores de desempenho que foram selecionados por meio de entrevistas com os participantes dos projetos de ME. Estes indicadores foram criados pelas próprias pessoas que participaram dos projetos do grupo do Núcleo de Manufatura Avançada (NUMA) da Escola de Engenharia de São Carlos, de acordo com a necessidade e sua experiência prática.

O método desenvolvido por Doolen e Hacker (2005) é composto por seis áreas de impacto usadas como base para o desenvolvimento das perguntas relativas à adoção de práticas de $\mathrm{ME}$ : equipamentos e processos de manufatura; gerenciamento do chão de fábrica; desenvolvimento de novos produtos; gestão de fornecedores; relacionamento com o cliente e gestão da força de trabalho. Cada área possui de três a sete práticas enxutas.

Dos Reis e Barros (2005) apresentam um sistema de avaliação da ME utilizando indicadores integrados ao plano de negócio da empresa. O método é formado por cinco princípios: melhoria contínua; comprometimento das pessoas; padronização; qualidade e curto lead time. Possui ainda trinta e três elementos associados a estes princípios.

A ferramenta de avaliação de Taj $(2005,2008)$ e Taj e Morosan (2011) avalia nove áreas-chave da produção: estoque; trabalho em equipe; processos; manutenção; layout e movimentação; fornecedores; setup; qualidade; e planejamento e controle. Os resultados são exibidos em uma planilha de pontuação e um gráfico de perfil enxuto mostra a situação da planta e as oportunidades em relação a seus objetivos enxutos.

Bonavia e Marin (2006) apresentam um método para avaliar o grau de utilização das práticas mais representativas da $\mathrm{ME}$, a sua relação com o tamanho da planta e seu efeito sobre o desempenho operacional da empresa. A coleta de dados é realizada por 11 questões, sendo que 5 delas são coletadas por meio de observação direta no chão de fábrica.

Cumbo, Kline e Bumgardner (2006) investigam o estado atual com relação à implementação de conceitos enxutos e técnicas de fabricação em indústrias madeireiras. Em seu estudo, consideraram indicadores de benchmarking da ME que incluem estatísticas de prazo de entrega do pedido, nível de estoque e variabilidade da demanda.

Utilizando princípios da álgebra vetorial Lucato, Maestrelli e Vieira Júnior (2006) propõem uma grandeza, denominada "grau de enxugamento", que procura medir o grau de implementação de elementos das normas SAE J4000 (SOCIETY..., 1999a) (Identificação e adoção de melhores práticas na execução de uma operação enxuta) e SAE J4001 (SOCIETY..., 1999b) (Manual do usuário para a efetivação de uma operação enxuta), possibilitando também definir uma grandeza capaz de medir o grau de execução de uma operação enxuta para a empresa toda.

Matsui (2007) utiliza quatro blocos principais para avaliar a ME: (1) organização e gestão dos recursos humanos; (2) gestão da qualidade, sistemas de informação da produção, sistemas de produção JIT; (3) desenvolvimento tecnológico e estratégia de manufatura; (4) desempenho competitivo. Cada bloco é composto por 4 a 7 questões com escala Likert de cinco pontos, gerando o diagnóstico de implantação da ME.

Ray et al. (2006) desenvolvem uma medida denominada índice enxuto para investigar, avaliar e medir o estado atual das operações de manufatura em indústrias madeireiras com relação a ME. Este método utiliza a técnica de análise fatorial em torno de dez variáveis: madeira consumida; produtividade; energia; outras matérias-primas consumidas; estoque total; produtos defeituosos; estoque de suprimentos; giro de estoque de matéria-prima; giro de estoque de produto acabado e em processo; e giro de estoque de produto acabado. 
Srinivasaraghavan e Allada (2006) avaliam a ME por meio da distância de Mahalanobis, utilizando cinco variáveis: 1 . Relação da diferença entre a demanda máxima anual e a demanda mínima anual, dividido pelo demanda anual máxima; 2 . Tempo de setup; 3 . Percentual de sucata em relação às vendas; 4. Percentual de entregas em dia dos fornecedores; 5. Número de eventos kaizen por ano. Depois da execução das quatro etapas do método, são criados vários cenários de implementação enxuta (soluções) que se encaixam de acordo com o orçamento financeiro da empresa.

Shah e Ward (2007) propõem um conjunto 10 fatores, que se subdividem em 41 itens para medir a ME e suas principais práticas. Dos 10 fatores identificados, três deles medem o envolvimento do fornecedor, um avalia o cliente e os demais tratam de questões internas à empresa. A coleta de dados é realizada por meio de perguntas associadas aos indicadores, demonstrando a extensão de implementação de cada prática da ME.

De acordo com a proposta de Bayou e Korvin (2008), o conjunto de práticas relevantes para uma organização se tornar enxuta foca-se em três práticas: JIT, kaizen/melhoria contínua e gestão da qualidade. O método é executado por meio da lógica fuzzy, seguindo nove passos para chegar a uma medida do grau de quanto a empresa analisada é enxuta em relação a uma empresa benchmarking selecionada pelo método. O resultado é apresentado, classificando a empresa como enxuta, medianamente enxuta ou muito enxuta.

Dias, Fernandes e Godinho Filho (2008) apresentam uma metodologia baseada em indicadores de desempenho, viabilizada por meio de um algoritmo. A escolha dos indicadores é baseada em três características: objetivos de desempenho da produção priorizados pela empresa; abrangência da aplicação; e princípios já implantados ou que serão implantados pela empresa.

Do Valle et al. (2008) apresentam o método Benchmarking Enxuto (BME). A primeira etapa deste método estabelece a formação das pessoas por meio de treinamento na ferramenta de coleta de dados. Na segunda etapa, procede-se à investigação dos 37 indicadores relacionados às variáveis demanda, produto, PCP e chão de fábrica, via aplicação do questionário que se divide entre indicadores de prática e desempenho. Na última fase, utilizam-se gráficos para análise das variáveis coletadas.

O método de Nogueira e Saurin (2008) possui 8 etapas para avaliação do nível de implementação das práticas da ME, focando-se na estratégia da empresa, aspectos culturais e organizacionais por meio das normas SAE J4000 (SOCIETY..., 1999a) e SAE J4001 (SOCIETY..., 1999b). Depois da aplicação do checklist, é realizado um seminário com gerentes das áreas de manutenção, produção, vendas, compras, PCP, engenharia de produto e administrativo para validação e consenso dos resultados coletados.

O método de Saurin e Ferreira (2008) tem como objetivo avaliar qualitativamente a implantação da ME. Com base em um conjunto de doze práticas da ME, é aplicada uma lista de verificação, composta por oitenta e oito itens. Cada possibilidade de resposta da lista de verificação possui um peso diferenciado que compõe a equação que calcula a nota de cada prática avaliada.

Wan e Chen (2008) quantificam o quão enxuto se apresenta o sistema de manufatura baseado na técnica de Análise Envoltória de Dados. Os processos de produção atuais são chamados de unidades tomadoras de decisões atuais (UTDA). Para obter um benchmarking enxuto viável, são criadas as unidades tomadoras de decisão ideais (UTDI). Por meio das UTDA e UTDI são criados diferentes cenários que avaliam trade off entre custo, lead time produtivo e valor agregado ao produto, aliados a decisões estratégicas da empresa.

O método desenvolvido por Gurumurthy e Kodali (2009) propõe avaliar onde se posiciona uma empresa que está implantando ou já implantou a ME quando comparada com outras organizações consideradas benchmarking. A avaliação do estado atual é feita por meio de 65 elementos enxutos e seleção das 90 medidas de desempenho relacionadas à ME e ao Sistema Toyota de Produção.

Wan e Chen (2009) introduzem uma abordagem que se adapta, de acordo com o sistema produtivo da empresa e do conhecimento e experiência de seus profissionais, em ME. O método é conduzido por meio de um software que orienta os usuários com questionários personalizados para avaliar o sistema produtivo de acordo com suas características.

Rahman, Laosirihongthong e Sohal (2010) examinam a extensão em que práticas enxutas são adotadas e seu impacto operacional no desempenho das empresas. Usando análise fatorial, estas práticas são agrupadas em três constructos: JIT, minimização de desperdícios e gerenciamento do fluxo. Por meio de modelos de regressão múltipla, o efeito das práticas enxutas sobre o desempenho operacional é investigado.

O método de Singh, Garg e Sharma (2010) utiliza uma equipe de cinco profissionais especializados em ME para medir o quanto uma empresa é considerada enxuta, com base em cinco parâmetros: fornecedor; prioridade de investimentos; práticas enxutas; desperdícios; e problemas de clientes. Os especialistas em ME consideram a história e objetivos dos parâmetros do método e, em seguida, definem uma escala de medida variando de aceitável a totalmente satisfatória. Finalmente, é aplicada a lógica fuzzy e os dados obtidos são convertidos em forma de índice de enxugamento. 
Behrouzi e Wong (2011) propõem um modelo para avaliar a ME baseado na lógica fuzzy que segue os seguintes passos: i) determinar os atributos de desempenho que se baseiam nas práticas enxutas de eliminação de desperdícios e produção puxada; ii) identificar as categorias de desempenho (qualidade, custo, tempo e JIT) e métricas para cada uma destas categorias; iii) setar a lógica fuzzy para cada métrica de desempenho; e iv) calcular as pontuações obtidas pela lógica fuzzy. O índice final que representa o quão enxuta a empresa se encontra é realizado mediante o cálculo da média de cada métrica.

No método proposto por Bhasin (2011), a ME é avaliada considerando 104 índices distribuídos entre 12 categorias. Mediante as pontuações obtidas por meio destes índices, é apresentado o resultado da avaliação da ME, que pode variar progressivamente entre diferentes estágios: Planejamento; Desenvolvimento; Mecânica; Avançada; Holística; Inovadora; e Ideológica.

O método de Eswaramoorthi et al. (2011) propõe examinar o grau com que as práticas enxutas estão sendo utilizadas. $\mathrm{O}$ instrumento de coleta de dados aborda o estado de implementação de ME, a motivação, os desafios para sua implantação, a frequência do uso de diferentes práticas enxutas e avaliação do nível de desperdícios.

Hofer et al. (2011) analisam as diferenças do nível de adoção das práticas da ME em indústrias da China e Estados Unidos. As respostas foram medidas em escala Likert de 5 pontos variando de "0" (sem implementação) a "5" (implementação completa) e os dados são analisados por meio de análise de regressão. A pesquisa aponta que práticas da ME estão sendo extensivamente adotadas na China nos diferentes setores das indústrias pesquisadas.

Seyedhosseini et al. (2011) apresentam um método que se baseia no Balanced Scorecard e utiliza cinco perspectivas para avaliação do desempenho da ME: i) financeira; ii) cliente; iii) processos; iv) pessoas; e v) fornecedores. Dentro destas perspectivas são gerados 16 objetivos enxutos por meio da técnica Delphi, e destes objetivos decorrem as 52 medidas que compõem o modelo. Além disso, o método emprega o Decision Making Trial and Evaluation Laboratory (DEMATEL), uma técnica para determinar a importância e prioridades entre os objetivos e as medidas enxutas combinadas com opiniões de especialistas em ME.

Vinodh e Balaji (2011) apresentam um modelo para avaliar o quão enxuta é uma fábrica por meio de um sistema informatizado denominado sistema de apoio à decisão para avaliação da ME. Este sistema calcula o índice enxuto e identifica as áreas mais fracas e potenciais que precisam ser melhoradas.

Vinodh e Chintha (2011) apresentam um método de avaliação da ME formado por três níveis. O primeiro é composto de cinco facilitadores enxutos (responsabilidade da gestão, administração da produção, força de trabalho, tecnologia e estratégia de manufatura). O segundo nível consiste de 20 critérios enxutos associados a cada facilitador. E o terceiro, é composto por vários atributos que são atrelados a cada critério do segundo nível. Para cada critério, cinco especialistas em ME escolhem uma entre cinco notas $(10,8,6,4,2)$. Finalmente, estas notas são aplicadas por meio da lógica fuzzy e é gerado um índice que representa quão enxuta a empresa se encontra.

Vinodh, Prakash e Selvan (2011) usam a lógica fuzzy aliada à técnica de mineração de dados proposta por Jain, Benyoucef e Deshmukh (2008). Os atributos para avaliar a ME neste método baseiam-se em unidades de decisão quantitativa (custo) e qualitativas (rentabilidade, produtividade, qualidade, lead time, defeitos e disponibilidade).

Anvari, Zulkifli e Yusuff (2012) apresentam uma abordagem para medir a influência de atributos enxutos utilizando a lógica fuzzy. Os atributos utilizados são: lead time, custo, defeito e valor, que são considerados pelos autores os mais importantes para alcançar a plena implantação enxuta. Uma pontuação com base nestes atributos é calculada para dar aos gestores uma visão real sobre o nível de implantação enxuta, mostrando a forma apropriada para melhorar ainda mais. De modo geral, permite uma medição sistemática da influência de atributos enxutos apresentando uma pontuação integrada sobre a avaliação realizada.

Azevedo et al. (2012) propõem um índice para avaliar tanto a agilidade quanto o nível de implantação enxuta das empresas que compõem uma cadeia de suprimentos. O índice denominado Agilean é obtido a partir de um conjunto de práticas da cadeia de suprimentos ágil e enxuta que são integrados em um modelo de avaliação. O método utiliza a técnica Delphi para desenvolver uma série de valores ponderados para as práticas ágeis e enxutas, gerando uma pontuação para comparar as empresas concorrentes e da cadeia de suprimentos.

Bhasin (2012) avalia a ME com base no Balance Scorecard. O modelo é dividido em 5 categorias (finanças, cliente, processo, pessoas e, futuro da organização) e é composto por 36 índices derivados destas categorias utilizados para julgar o impacto real da ME nas organizações. Primeiramente foi aplicado um survey com 68 empresas e, posteriormente, estudos de casos foram conduzidos em 7 destas empresas para validar os resultados da pesquisa.

Com um questionário de escala Likert de 7 pontos, variando de "discordo totalmente" até "concordo fortemente" composto por 53 questões, Chauhan e Singh (2012) aplicaram survey em médias e grandes empresas da Índia, que foi analisado por meio do método da Análise Hierárquica - Analytical Hierarchy Process (AHP). Os parâmetros incorporados 
ao questionário avaliam questões relacionadas à eliminação de desperdícios, melhoria contínua, zero defeitos, entregas JIT, produção puxada, força de trabalho multifuncional, descentralização, integração de funções e sistema de informações vertical. As questões relacionadas a estes parâmetros foram também avaliadas pelos executivos das indústrias entrevistadas e por acadêmicos da área.

O modelo de avaliação da ME de Cil e Turkan (2012) é conduzido por meio da abordagem Analytic Network Process (ANP). O primeiro passo para sua execução é a formação de um grupo de decisores especialistas em ME, composto por representantes experientes da alta gerência de vários setores da empresa para discutir os objetivos da transformação enxuta. O segundo passo é construir a estrutura dos objetivos e organizá-los de modo a descrever em detalhes o que a empresa deseja alcançar e, então, incorporar esses objetivos de forma adequada em um modelo de decisão. Na sequência, as práticas enxutas são incorporadas ao modelo e estabelecidas as relações para que sejam determinadas as prioridades a serem tomadas.

Nasab, Bioki e Zare (2012) apresentam o método denominado $\mathrm{A}^{2}$, uma abordagem que usa a técnica AHP como entrada para o modelo de Redes Neurais Artificiais - Artificial Neural Network (ANN). O resultado classifica a empresa em três níveis: enxuta, mais enxuta ou muito enxuta. Segundo os autores do modelo, aumento de velocidade de implantação, diminuição de custo, capacidade de analisar vários cenários enxutos em curto espaço de tempo e baixo custo, são algumas das vantagens do método proposto.

Unver (2012) propõe a abordagem de inteligência de manufatura, denominada Manufacturing Operations Center (MOC), que incorpora as ferramentas necessárias para apoiar a filosofia de melhoria contínua da ME com ampla capacidade de resposta, fornecendo informações em tempo real das operações de chão de fábrica. Possui 55 indicadores de desempenho que apresentam integração entre o Enterprise Resource Planning (ERP) e o chão de fábrica e é baseada na norma International Society of Automation 95 (ISA95), que foca-se no desenvolvimento de interface automática entre empresa e sistemas de controle.

Vinodh e Vimal (2012a) apresentam um modelo dividido em três níveis denominados viabilizadores, critérios e atributos enxutos. O modelo foi validado por meio de um estudo de caso em uma indústria fabricante de materiais elétricos. Especialistas avaliaram a classificação de desempenho das capacidades lean atribuindo-lhes pesos por meio de variáveis qualitativas (worst, very poor, fair, good, very good, excellent) e, utilizando a lógica fuzzy, estabeleceram o Fuzzy Leanness Index (FLI) e o Fuzzy Performance Importance Index (FPII). O FLI apresenta o nível lean da organização, já o FPII é calculado para encontrar os obstáculos que impedem a ME de evoluir.

Utilizando a abordagem das regras de if-then proposta por Tsourveloudis e Valavinis (2002) que avalia agility de uma organização, Vinodh e Vimal (2012b) ampliaram o trabalho de Vinodh e Vimal (2012a), estendendo-o para avaliar a ME. O modelo proposto consiste de 5 viabilizadores enxutos, 30 critérios enxutos e 59 atributos. Os viabilizadores enxutos estão centrados em i) responsabilidade de gestão; ii) gestão de produção; iii) força de trabalho enxuta; iv) tecnologia enxuta; e v) estratégia de manufatura.

Zhou (2012) investiga as práticas enxutas em Pequenas e Médias Empresas (PME), discutindo benefícios e revelando fatores que são capazes de impedir ou dificultar o processo de implantação da ME. Os procedimentos necessários para garantir uma implantação enxuta bem sucedida são avaliados com um questionário composto por cinco áreas: i) compreensão de conceitos da filosofia enxuta; ii) percepção dos fatores da condução da implantação da ME; iii) estado da implantação das práticas da ME; iv) benefícios da implantação da ME; e v) desafios na implantação da ME. Em geral, o estudo fornece melhor compreensão das estratégias enxutas e como elas são utilizadas por pequenas organizações, apresentando ideias para projetar e implantar estratégias para melhorar a eficácia de organizações de pequeno porte.

\section{Resultado da classificação dos artigos estudados}

Para permitir a visualização de todas as informações analisadas por artigo estudado, os resultados são apresentados em tabelas disponíveis nos Apêndices 1 e 2.

A seguir, são apresentados os principais resultados desta pesquisa, sendo que, no Apêndice 1, é apresentado o detalhamento dos 48 artigos estudados conforme os parâmetros de caracterização propostos na seção 3 , com exceção do parâmetro práticas da $\mathrm{ME}$ avaliadas, que é apresentado no Apêndice 2.

A abordagem metodológica empregada nos métodos de avaliação da ME apresentou-se bem distribuída entre estudo de caso e survey, com 16 publicações cada um. Estudo teórico-conceitual (LUCATO; MAESTRELLI; VIEIRA JÚNIOR, 2006) e estudo de campo (NIGHTINGALE; MIZE, 2002) foram identificados em apenas uma publicação cada um. Publicações que não mencionaram o tipo de abordagem metodológica totalizam 14 artigos. Apenas Bhasin (2012) utilizou a abordagem multimétodo, aplicando tanto o survey quanto o estudo de caso.

"Manufatura" foi o foco presente em todos os métodos identificados. Apenas três publicações apresentaram maior abrangência (NIGHTINGALE; MIZE, 2002; DIAS; FERNANDES; 
GODINHO FILHO, 2008; GURUMURTHY; KODALI, 2009), avaliando "manufatura, cadeia de suprimentos e empresa". Com relação às publicações que avaliam "manufatura e cadeia de suprimentos", tem-se Sánchez e Pérez (2001), Shah e Ward (2007), Nogueira e Saurin (2008), Saurin e Ferreira (2008), Singh, Garg e Sharma (2010), Eswaramoorthi et al. (2011), Hofer et al. (2011), Seyedhosseini et al. (2011), Vinodh e Chintha (2011), Azevedo et al. (2012), Bhasin (2012) e Cil e Turkan (2012), que representam $25 \%$ das publicações. Já as publicações que analisam "manufatura e empresa", tem-se Karlsson e Ahlström (1996) e Lucato, Maestrelli e Vieira Júnior (2006).

Verificou-se que predomina como quantitativa em 31 dos métodos a forma de apresentação do diagnóstico de avaliação da ME. Já as formas qualitativa e qualitativa-quantitativa estão presentes em 7 e 9 publicações, respectivamente. A predominância da forma de apresentação do diagnóstico quantitativa se deve, em alguns casos, ao uso de técnicas como a lógica fuzzy, encontrada em Bayou e Korvin (2008), Singh, Garg e Sharma (2010), Behrouzi e Wong (2011), Vinodh e Balaji (2011), Vinodh e Chintha (2011), Vinodh, Prakash e Selvan (2011), Anvari, Zulkifli e Yusuff (2012) e Vinodh e Vimal (2012a, 2012b); o método AHP utilizado por Azevedo et al. (2012), Chauhan e Singh (2012); análise fatorial empregada por Ray et al. (2006), Shah e Ward (2007) e Rahman, Laosirihongthong e Sohal (2010); distância de Mahalanobis usada por Srinivasaraghavan e Allada (2006); análise envoltória de dados utilizada por Wan e Chen (2008); Balanced Scorecard aplicado por Seyedhosseini et al. (2011) e Bhasin (2012); análise de regressão adotada por Hofer et al. (2011); abordagem ANP usada por Cil e Turkan (2012). Já Unver (2012) baseia-se na norma ISA-95 para compor o seu modelo de avaliação da ME. Demais autores desenvolvem suas próprias formas de avaliar a ME quantitativamente. Cada indicador dos princípios de Sánchez e Pérez (2001) é avaliado verificando se deve aumentar ou diminuir para contribuir no avanço para ME. Goodson (2002) utiliza a taxa de RPA com uma escala que vai de "fraco" (1) a "best in class" (11). A pontuação total desta escala para todas as categorias ficará entre 11 (fraca em todas as categorias) e 121 (a melhor em todas as categorias), com uma pontuação média de 55. O resultado da avaliação das quatro seções (Materiais e Inventário; Treinamento; Manutenção Preventiva; e Qualidade) de Kumar e Thomas (2002) é gerado em arquivo texto ou Excel, mostrando os percentuais da implementação das práticas enxuta de cada seção. Os indicadores de desempenho apresentados por Cardoza e Carpineti (2005) e Dos Reis e Barros (2005) são compostos por fórmulas que representam indicadores de avaliação, como, por exemplo: índice de entrega ao cliente-fornecedor, índice de atrasos do cliente-fornecedor, giro de estoque, produtividade, absenteísmo, entre outros. Cinco níveis de maturidade foram desenvolvidos para cada prática do método de Nightingale e Mize (2002), que vão de pouco capaz (Nível 1) em nível de classe mundial (Nível 5) e representam uma evolução na capacidade da organização em relação a prática enxuta avaliada de cada seção do método. O índice de adoção da ME de Kojima e Kaplinski (2004) é gerado mediante a média das pontuações em cada um dos três índices considerados pelo método, gerando uma classificação da empresa como forte, média ou fraca. Lucato, Maestrelli e Vieira Júnior (2006) usam álgebra vetorial, para gerar uma grandeza que mede o grau de implementação de determinados elementos das normas SAE J4000 (SOCIETY..., 1999a) e SAE J4001 (SOCIETY..., 1999b). O questionário de Do Valle et al. (2008) utiliza uma escala de números inteiros de 1 a 5 para avaliar a aplicação de uma prática ou obtenção de um desempenho com relação a ME ( 1 = nível básico; 3 = nível intermediário; $5=$ excelência). Cada questão que avalia os indicadores do método de Wan e Chen (2009) contém várias opções de resposta que representam o nível de conformidade para o indicador enxuto e sugestões de melhoria correspondentes predefinidas, assim são criadas matrizes com pesos para todos os indicadores para identificar melhorias e determinar o estado atual da empresa avaliada.

A Figura 2 apresenta a concentração do tipo de dinâmica de aplicação do diagnóstico da ME por período. Destaca-se o nível tático, que está associado a 40 dos 48 métodos analisados. Métodos voltados exclusivamente ao nível tático somam 25 publicações, estando ausente somente nos anos de 1996, 2001, 2004 e 2009.

A atuação do nível operacional também é expressiva, estando presente em 15 métodos e em todo o período, apresentando inclusive maior frequência que o nível estratégico, que está presente em 12 dos 48 métodos. Apenas cinco métodos (WAN; CHEN, 2008; CHAUHAN; SINGH, 2012; CIL; TURKAN, 2012; NASAB; BIOKI; ZARE, 2012; ZHOU, 2012) são direcionados exclusivamente ao nível estratégico. A dinâmica de aplicação do diagnóstico direcionada exclusivamente ao nível estratégico, tático e operacional simultaneamente está presente apenas em 5 métodos (SORIANO-MEIER; FORRESTER, 2002; DOS REIS; BARROS, 2005; MATSUI, 2007; WAN; CHEN, 2009; ESWARAMOORTHI et al., 2011).

Os países que apresentam a menor quantidade de publicações são: África, Japão, Suécia, Tailândia e Portugal, com apenas 1 publicação cada um. Por outro lado, Estados Unidos é o país que apresenta a maior quantidade, com 15 publicações. Na sequência, tem-se a Índia, com 9 e o Brasil, com 7. Inglaterra 


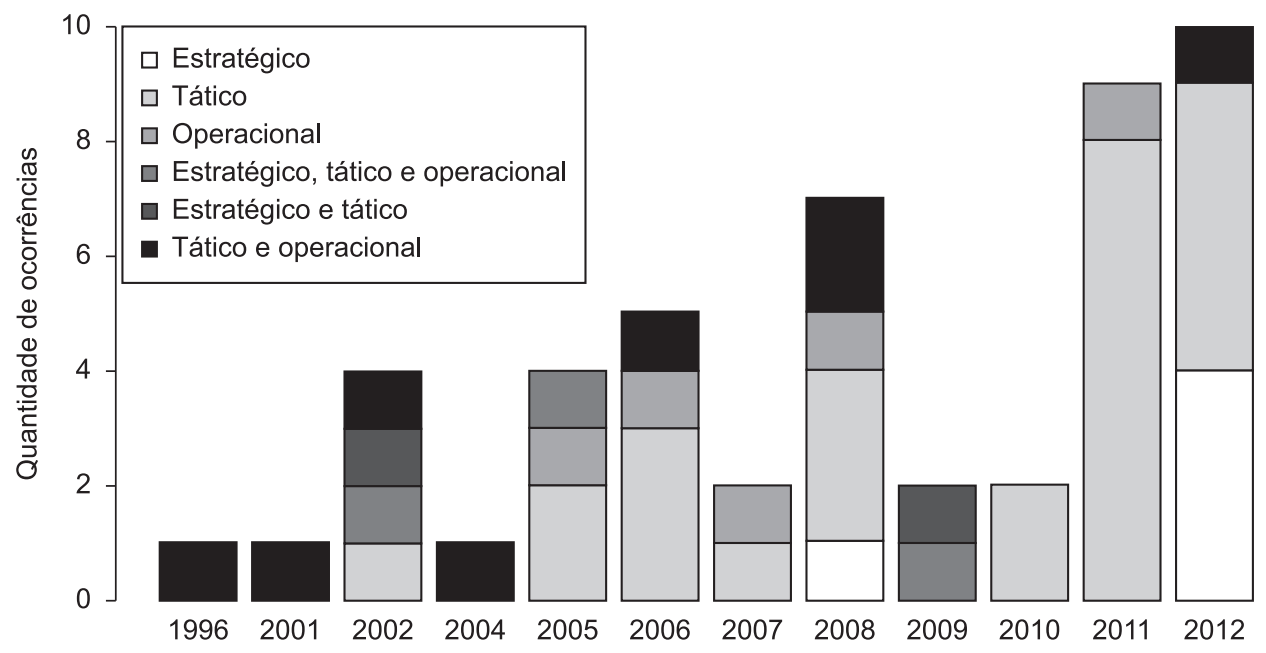

Figura 2. Característica dos artigos quanto à dinâmica de aplicação.

tem 3 publicações e, Espanha, Malásia, Irã e Turquia têm 2 publicações cada um.

Os setores industriais nos quais os métodos foram aplicados é bem variado, englobando a indústria de eletrônico, eletroeletrônico, materiais elétricos, automotiva, componentes para automóveis, máquinas, aeroespacial, gráfica, bebida, cerâmica, moveleira, instrumentos médicos, metal-mecânico, metalúrgica, telecomunicação, alimento, farmacêutico, química, vestuário e têxtil. No entanto, observou-se que há mais aplicações em indústrias fabricantes de eletrônicos.

Entre as sete publicações, nas quais não houve aplicação do método desenvolvido, cinco delas apresentam a aplicação por meio de um exemplo, é o caso de Lucato, Maestrelli e Vieira Júnior (2006), Wan e Chen (2008) e Behrouzi e Wong (2011), Anvari, Zulkifli e Yusuff (2012) e Unver (2012). Kumar e Thomas (2002) apenas orientam como utilizar o software desenvolvido. Já Cardoza e Carpinetti (2005) apresentam uma discussão sobre os indicadores de desempenho para avaliação da ME utilizados por fabricantes de máquinas agrícolas.

Das 48 publicações identificadas, 13 delas baseiam-se em métodos de avaliação da ME desenvolvido por outros autores. Sánchez e Pérez (2001) e Soriano-Meier e Forrester (2002) utilizam uma lista de verificação em seu método, sendo que alguns dos indicadores apresentados já foram propostos por Karlsson e Ahlström (1996). Soriano-Meier e Forrester (2002) também baseiam parte de seu questionário de coleta de dados em Boyer (1996) que examina quatro investimentos em infraestrutura considerados importantes para apoiar um programa de Gestão da Qualidade Total ou JIT. Bonavia e Marin (2006) baseiam seu instrumento de coleta de dados nos trabalhos de White, Pearson e Wilson (1999), Karlsson e Ahlstöm (1996) e Jackson e Dyer (1998). Do Valle et al. (2008) utilizam o método BME desenvolvido por Andrade (2006). Taj (2005, 2008) e Taj e Morosan (2011) desenvolvem seus estudos utilizando a proposta de Lee (2011). Lucato, Maestrelli e Vieira Júnior (2006) e Nogueira e Saurin (2008) baseiam-se nas normas SAE J4000 (SOCIETY..., 1999a) e SAE J4001 (SOCIETY..., 1999b) para avaliar a ME. A avaliação das práticas do checklist de Nogueira e Saurin (2008) são semelhantes ao de Saurin e Ferreira (2008) e é possível avaliá-las atribuindo um peso específico para cada resposta do questionário de coleta de dados e, posteriormente, calcula-se uma nota para cada prática da ME. Dias, Fernandes e Godinho Filho (2008) fundamentam seu instrumento de coleta de dados nos indicadores propostos por Karlsson e Ahlström (1996) e Sánchez e Pérez (2001). Hofer et al. (2011) fundamentam seu método de avaliação no questionário de Shah e Ward (2007). Chauhan e Singh (2012) têm como base de seu método de avaliação a proposta de Karlsson e Ahlström (1996) e Soriano-Meier e Forrester (2002). Já Vinodh e Vimal (2012b) ampliam a proposta apresentada em Vinodh e Vimal (2012a).

Uma das publicações não se baseia em um método específico de avaliação, mas utiliza práticas da ME de outro trabalho relacionado ao assunto, é o caso de Rahman, Laosirihongthong e Sohal (2010), que usam 13 das 21 práticas de gerenciamento propostas por Shah e Ward (2003) por estarem associadas aos sistemas enxutos. Outras duas publicações Singh, Garg e Sharma (2010) e Vinodh, Prakash e Selvan (2011) empregam modelos utilizados na avaliação da cadeia de suprimentos. Singh, Garg e Sharma (2010) aplicam a lógica fuzzy de acordo com o modelo proposto por Chan et al. (2003) e Vinodh, Prakash e Selvan (2011) utilizam a abordagem da lógica fuzzy na mineração de dados proposta por Jain, Benyoucef e Deshmukh (2008). Seyedhosseini et al. (2011) e Bhasin (2012) não se baseiam em métodos 
de avaliação da ME anteriormente publicados, mas estão baseados no Balanced Scorecard, um tradicional método de avaliação de desempenho.

Mais da metade das publicações $(58,3 \%)$ apresenta o instrumento de coleta de dados completo utilizado para avaliar a ME. Kumar e Thomas (2002) não apresentam o questionário de coleta de dados na publicação, porém indicam nas referências site para download do software em que pode ser verificado o método completo. Estas publicações possibilitam que outros pesquisadores e profissionais da área possam facilmente aplicá-los em suas instalações, uma vez que além do instrumento de coleta de dados, todas as publicações detalham a dinâmica de aplicação do método desenvolvido.

Apenas 18,7\% das publicações ( 9 artigos) indicaram recebimento de suporte financeiro para condução da pesquisa. Cabe ressaltar que existência de suporte financeiro é caracterizada mediante as evidências mencionadas na própria publicação analisada. Deste modo, aparentemente, a maioria das pesquisas é realizada com recursos próprios, ou recursos já disponíveis nas universidades, pressupondo-se que não houve financiamento específico.

As práticas da $\mathrm{ME}$ avaliadas por cada método de avaliação da ME são apresentadas no Apêndice 2. Considerando os métodos que avaliam a maior quantidade de práticas, tem-se Gurumurthy e Kodali (2009). Na sequência, vem Singh, Garg e Sharma (2010), que não avaliam apenas a prática de "Padronização das operações" e Eswaramoorthi et al. (2011) que não consideram a prática de "Engenharia simultânea". Por outro lado, os métodos que avaliam a menor quantidade de práticas são Ray et al. (2006) e Vinodh, Prakash e Selvan (2011), que avaliam a prática de "Defeitos/ Controle de Qualidade" e Wan e Chen (2008) que avaliam "Mapeamento do Fluxo do Valor".

A Tabela 1 apresenta a frequência das práticas da ME avaliadas pelos métodos de avaliação investigados. A prática da ME mais avaliada é "Sistema Puxado de Produção" presente em $75,0 \%$ das publicações. $\mathrm{Na}$ sequência, tem-se "Troca Rápida de Ferramentas" $(68,70 \%)$, "Integração de fornecedores" (60,4\%), "Força de trabalho multifuncional" e "Defeitos/ Controle de Qualidade" (ambos com 58,3\%). Por outro lado, as práticas da ME menos avaliadas são "Engenharia Simultânea" e "Autonomação/Jidoka", presente apenas em 16,7\% e 18,7\% dos métodos de avaliação da ME, respectivamente. Outras práticas menos avaliadas encontradas em 22,9\% das publicações são: "Controle Estatístico da Qualidade" e "Entregas JIT de fornecedores".

Outras considerações quanto às práticas da ME avaliadas são as seguintes: Kumar e Thomas (2002), Azevedo et al. (2012), Vinodh e Vimal (2012a, b) e Zhou (2012) avaliam sistemas Pokayoke. Kumar e Thomas (2002) avaliam ainda questões relacionadas à segurança e ergonomia dos trabalhadores, bem como certificação da qualidade. E Zhou (2012) avalia também práticas de benchmark. Práticas Seis Sigma estão presentes nos métodos de avaliação da ME de Azevedo et al. (2012) e Zhou (2012). Azevedo et al. (2012) ainda avaliam a existência de relações privilegiadas entre a organização e clientes para compartilhamento de informações alinhadas com as necessidades dos clientes.

Nightingale e Mize (2002) consideram ainda na avaliação da ME: o feedback do cliente, interações entre vendas e marketing alinhadas à produção e se o sistema financeiro da empresa suporta a transformação enxuta, englobando também saúde e segurança dos funcionários. O método de Cumbo, Kline e Bumgardner (2006) não avalia diretamente as práticas da ME consideradas neste estudo, porém avalia a frequência dos seguintes itens considerados pelos autores fatores de desempenhos de benchmarking para a ME: quantidade de embarques de material livre de erros, salário, rotatividade e satisfação dos colaboradores, volumes de vendas, entregas no prazo, margem de lucro, lead time e satisfação do cliente. Finalmente, Matsui (2007), além das práticas apontadas no Apêndice 2, avalia também a adoção do JIT pelo sistema MRP (Material Requirements Planning) da empresa.

Além das práticas da Tabela 1, Cil e Turkan (2012) avaliam o uso de tecnologia da informação, Hoshin Kanri, modularização, aplicação de Quality Function Deployment (QFD), uso de automação, avaliação de investimentos e necessidade de recursos e envolvimento do cliente no projeto do produto e programas de qualidade. Já Seyedhosseini et al. (2011) e Bhasin (2012) consideram aspectos de satisfação do cliente na avaliação da ME.

\section{Conclusões}

Por meio de uma pesquisa bibliográfica, este artigo apresentou os métodos científicos de avaliação da ME, buscando identificar suas principais características. Os parâmetros utilizados para alcançar este objetivo centraram-se em identificar nas publicações: o tipo de abordagem metodológica utilizada; foco de avaliação; forma de apresentação do diagnóstico de avaliação; dinâmica de aplicação do diagnóstico de avaliação; e práticas clássicas da $\mathrm{ME}$ avaliadas.

Apesar da quantidade de abordagem metodológica survey ter se igualado a estudo de caso, pode-se considerar que esta última ainda vem sendo utilizada com bastante frequência em pesquisas na área de engenharia de produção. O que corrobora com estudos de Berto e Nakano (2000) e Miguel (2007), os quais apontam o estudo de caso como a abordagem metodológica mais utilizada na área.

O foco de avaliação da ME contemplando "manufatura, cadeia de suprimentos e empresa" foi 
Tabela 1. Frequência das práticas da Manufatura Enxuta dos métodos de avaliação.

\begin{tabular}{lcc}
\hline \multicolumn{1}{c}{ Práticas da manufatura enxuta } & Frequência & $\begin{array}{c}\text { \% em relação à quantidade de } \\
\text { métodos }\end{array}$ \\
\hline Sistema Puxado de Produção & 36 & 75,0 \\
Troca Rápida de Ferramentas & 33 & 68,7 \\
Integração de fornecedores & 29 & 60,4 \\
Defeitos/Controle de Qualidade & 28 & 58,3 \\
Força de trabalho multifuncional & 28 & 58,3 \\
Manutenção Produtiva Total & 24 & 50,0 \\
Gestão Visual & 21 & 43,7 \\
Equipes de resolução de problemas & 19 & 39,6 \\
5S & 19 & 39,6 \\
Tecnologia de Grupo/Manufatura Celular & 18 & 37,5 \\
Mapeamento do Fluxo do Valor & 17 & 35,4 \\
Sugestões de melhorias & 15 & 31,2 \\
Padronizaçao das operações & 16 & 33,3 \\
Nivelamento da Produção & 12 & 25,0 \\
Controle Estatístico da Qualidade & 11 & 22,9 \\
Entregas JIT de fornecedores & 11 & 22,9 \\
Autonomação/Jidoka & 9 & 18,7 \\
Engenharia Simultânea & 8 & 16,7 \\
\hline
\end{tabular}

inexpressivo, presente apenas em torno de $6 \%$ das publicações, o que leva a considerar que a avaliação de aspectos da ME com foco na empresa toda ainda pode ser considerada um desafio. Já com relação ao foco de "manufatura e cadeia de suprimentos", observou-se uma quantidade relativamente maior (em torno de 25\%), o que sugere que os métodos estão evoluindo, mesmo que timidamente, e ampliando sua avaliação para além da manufatura.

A abordagem quantitativa poder ser considerada uma tendência que veio para estabelecer-se em termos de forma de apresentação do diagnóstico da avaliação da ME, uma vez que depois que foi utilizada pela primeira vez na publicação de Sánchez e Pérez (2001), manteve-se presente por todo o período analisado. Além de que, está presente em $87,5 \%$ das publicações.

A concentração do tipo de dinâmica de aplicação do diagnóstico da ME voltada ao nível tático é uma boa constatação, pois são as pessoas associadas a este nível que normalmente são os multiplicadores e repassam o conhecimento para os demais dentro da organização. Este é um fator de extrema importância, sobretudo quando estas informações são repassadas para o nível operacional, que tem grande impacto na implantação, bem como para o sucesso das práticas da ME.

Quanto às práticas da ME mais comumente encontradas nos métodos de avaliação, cabe ressaltar a presença da prática de "Integração de fornecedores" em mais da metade das publicações. Isso indica uma inclinação de foco de avaliação da ME em tratar além de suas práticas tradicionais, o estreitamento das relações entre fornecedores, levando os princípios e práticas enxutas além da extensão da empresa.

A pequena quantidade de publicações encontradas na revisão da literatura pode ser uma lacuna a ser explorada, em termos de desenvolvimento de métodos que avaliam a situação da implantação da ME. Isso reforça a ideia de alguns autores como Wan e Chen (2008), Behrouzi e Wong (2011) e Bhasin (2011), os quais afirmam que pouco esforço foi feito no desenvolvimento de métodos de avaliação de ME.

A escassez de pesquisas relacionadas ao tema também sugere que as empresas têm avaliado pouco a implantação da ME. Sem dúvida, a falta de uma compreensão clara sobre o desempenho desta implantação pode contribuir significativamente para o fracasso das práticas enxutas. Em outras palavras, não é possível gerenciar a ME sem avaliar seu desempenho.

\subsection{Oportunidades de novos desdobramentos para pesquisas futuras}

Com base na pesquisa bibliográfica realizada, esta seção apresenta as principais lacunas identificadas na literatura, que podem ser consideradas como oportunidades de novos desdobramentos para pesquisas futuras em termos de aperfeiçoamento e desenvolvimento de novos métodos de avaliação da ME.

O foco de alcance de avaliação da ME restringiu-se às categorias "manufatura", "cadeia de suprimentos" e "empresa". Não foi identificado nenhum método que avalie os princípios enxutos da ME em áreas 
específicas da organização, como, por exemplo, logística enxuta e lean office. Assim, de certa forma, evidencia-se que há espaço para ampliação do foco de avaliação da ME em futuros trabalhos.

É possível expandir a avaliação da ME para além de suas práticas e ferramentas tradicionais, considerando, por exemplo, os recursos humanos que têm fortes impactos, tanto positivos como negativos no processo de implantação da ME (WOMACK; JONES, 1992; LIKER, 2005; ACHANGA et al., 2006). Neste quesito, com exceção de Kumar e Thomas (2002) e Nightingale e Mize (2002), que avaliam segurança e ergonomia, nenhum outro trabalho fez alguma avaliação mais específica com relação à satisfação e ponto de vista dos trabalhadores com a implantação da ME.

Mesmo nos métodos quantitativos que apresentam o diagnóstico de implantação da ME em forma de escala progressiva, não há como avaliar sistematicamente a evolução de sua implantação. Neste sentido, existe a possibilidade de desenvolver algum mecanismo que quando aplicado às empresas já avaliadas, permita mostrar a evolução rumo à ME, indicando sistematicamente onde estas melhorias efetivamente ocorrem.

A ME tem como característica principal a eliminação de desperdícios, o que consequentemente leva à redução de custos, assim também é possível explorar o aperfeiçoamento de métodos de avaliação da ME que sejam capazes de expressar (avaliar) ganhos monetários com sua implantação em diferentes áreas da empresa.

Finalmente, cabe ressaltar que, independentemente da metodologia da pesquisa utilizada no aperfeiçoamento ou desenvolvimento de novos métodos de avaliação da ME, estes poderiam apresentar maior caracterização do rigor necessário para sua utilização (treinamento e requisitos mínimos necessários de domínio no assunto, por exemplo), para que sua aplicação não se restrinja aos pesquisadores que os desenvolvem, podendo ser aplicado também pela comunidade acadêmica e profissionais da área, haja vista a necessidade de atender à contínua busca pela melhoria da produtividade $\mathrm{e}$ desempenho da manufatura.

\section{Referências}

ACHANGA, P. et al. Critical success factors for lean implementation within SMEs. Journal of Manufacturing Technology Management, v. 17, n. 4, p. 460-471, 2006. http://dx.doi.org/10.1108/17410380610662889

AHLSTRÖM, P. Sequences in the implementation of lean production. European Management Journal, v. 16, n. 3, p. 327-334, 1998. http://dx.doi.org/10.1016/ S0263-2373(98)00009-7

ANAND, G.; KODALI, R. Development of a framework for implementation of lean manufacturing systems. International Journal of Management Practice, v. 4, n. 1, p. 95-116, 2010. http://dx.doi.org/10.1504/ IJMP.2010.029705

ANDRADE, G. J. P. O. Um método de diagnóstico do potencial de aplicação da Manufatura Enxuta na indústria têxtil. 2006. 297 f. Tese (Doutorado em Engenharia de Produção)-Universidade Federal de Santa Catarina, Florianópolis, 2006.

ANVARI, A.; ZULKIFLI, N.; YUSUFF, R. M. A dynamic modeling to measure lean performance within lean attributes. The International Journal of Advanced Manufacturing Technology, p. 1-15, Apr. 2012.

ARBOS, L. C.; SANTOS, J. F.; SÁNCHEZ, C. V. The operations-time chart: a graphical tool to evaluate the performance of production systems. from batch-andqueue to lean manufacturing. Computers \& Industrial Engineering, v. 61, n. 3, p. 663-675, 2011.

AZEVEDO, S. G. et al. An integrated model to assess the leanness and agility of the automotive industry. Resources, Conservation and Recycling, v. 66, p. 85-94, 2012. http:// dx.doi.org/10.1016/j.resconrec.2011.12.013

BAYOU, M. E.; KORVIN, A. Measuring the leanness of manufacturing system: A case study of Ford Motor Company and General Motors. Journal of Engineering and Technology Management, v. 25, n. 4, p. 287-304, 2008. http://dx.doi.org/10.1016/j. jengtecman.2008.10.003

BEHROUZI, F.; WONG, K. Y. Lean performance evaluation of manufacturing systems: a dynamic and innovative approach. Procedia Computer Science, v. 3, p. 388-395, 2011. http://dx.doi.org/10.1016/j. procs.2010.12.065

BERTO, R. M. V. S.; NAKANO, D. N. A produção científica nos anais do Encontro Nacional de Engenharia de Produção: um levantamento de métodos e tipos de pesquisa. Produção, v. 9, n. 2, p. 65-76, 2000. http:// dx.doi.org/10.1590/S0103-65131999000200005

BHASIN, S. Lean and performance measurement. Journal of Manufacturing Technology Management, v. 19 , n. 5, p. 670-684, 2008. http://dx.doi. org/10.1108/17410380810877311

BHASIN, S. Measuring the leanness of an organisation. International Journal of Lean Six Sigma, v. 2, n. 1, p. 55-74, 2011. http://dx.doi. org/10.1108/20401461111119459

BHASIN, S. Performance of Lean in large organisations. Journal of Manufacturing Systems, v. 31, n. 3, p. 349-357, 2012. http://dx.doi.org/10.1016/j. jmsy.2012.04.002

BHASIN, S.; BURCHER, P. Lean viewed as a philosophy. Journal of Manufacturing Technology Management, v. 17, n. 1, p. 56-72, 2006. http://dx.doi. org/10.1108/17410380610639506

BIAZZO, S.; PANNIZZOLO, R. The assessment of work organisation in lean production: the relevance of the worker's perspective. Integrated Manufacturing Systems, v. 11, n. 1, p. 6-15, 2000. http://dx.doi. org/10.1108/09576060010303622

BLACK, J. T. Design rules for implementing the Toyota production system. International Journal of Production Research, v. 45, n. 16, p. 3639-3664, 2007. http://dx.doi. org/10.1080/00207540701223469 
BONAVIA, T.; MARIN, J. A. An empirical study of lean production in the ceramic tile industry in Spain. International Journal of Operations and Production Management, v. 26, n. 5, p. 505-531, 2006. http:// dx.doi.org/10.1108/01443570610659883

BOYER, K. K. An assessment of managerial commitment to lean production. International Journal of Operations and Production Management, v. 16, n. 9, p. 48-59, 1996. http://dx.doi.org/10.1108/01443579610125589

CARDOZA, E.; CARPINETTI, L. C. R. Indicadores de desempenho para o sistema de produção enxuto. Produção Online, v. 5, n. 2, 2005. Disponível em: $<$ http://producaoonline.org.br/index.php/rpo/article/ view/338/433 >. Acesso em: 04 nov. 2011.

CARNEVALLI, J. A.; MIGUEL, P. A. C. Review, analysis and classification of the literature on QFD - Types of research, difficulties and benefits. International Journal Production Economics, v. 114, n. 2, p.737-754, 2008. http://dx.doi.org/10.1016/j.ijpe.2008.03.006

CHAKRAVORTY, S. S. An implementation model for lean programmes. European Journal of Industrial Engineering, v. 4, n. 2, p. 228-248, 2010. http://dx.doi. org/10.1504/EJIE.2010.031079

CHAN, F. T. S. et al. A conceptual model of performance measurement for supply chains. Management Decision, v. 4, n. 7, p. 635-642, 2003. http://dx.doi. org/10.1108/00251740310495568

CHAUHAN, G.; SINGH, T. P. Measuring parameters of lean manufacturing realization. Measuring Business Excellence, v. 16, n. 3, p. 57-71, 2012. http://dx.doi. org/10.1108/13683041211257411

CIL, I.; TURKAN, Y. S. An ANP-based assessment model for lean enterprise transformation. The International Journal of Advanced Manufacturing Technology, v. 29, Mar. 2012.

CRUTE, V. et al. Implementing lean in aerospace - challenging the assumptions and understating the challenges. Technovation, v. 23, n. 12, p. 917-928, 2003. http:// dx.doi.org/10.1016/S0166-4972(03)00081-6

CUMBO, D.; KLINE, D. E.; BUMGARDNER, M. S. Benchmarking performance measurement and lean manufacturing in the rough mill. Forests Product Journal, v. 56, n. 6, p. 25-30, 2006.

DIAS, T. F.; FERNANDES, F. C. F.; GODINHO FILHO, M. Uma metodologia baseada em indicadores de desempenho para avaliação da implantação da Manufatura Enxuta: proposta e estudo de caso. Gestão Industrial, v. 4, n. 2, p. 104-122, 2008. Disponível em: <http://www. pg.utfpr.edu.br/depog/periodicos/index.php/revistagi/ article/view/22/19>. Acesso em: 08 nov. 2011.

DOOLEN, T. L.; HACKER, M. E. A review of lean assessment in organizations: an exploratory study of lean practices by electronics manufacturers. Journal of Manufacturing Systems, v. 24, n. 1, p. 55-67, 2005. http://dx.doi.org/10.1016/S0278-6125(05)80007-X

DOS REIS, A. C. C.; BARROS, J. G. M. Avaliação dos resultados da implementação do Sistema Global de Manufatura em uma planta da General Motors do Brasil. Revista Brasileira de Gestão e Desenvolvimento Regional, v. 1, n. 1, p. 20-33, 2005. Disponível em: <http://www.rbgdr.net/revista/index.php/rbgdr/article/ viewArticle/79>. Acesso em: 04 out. 2011.

DO VALLE, A. C. R. et al. Aplicação do método Benchmarking Enxuto em uma empresa metal mecânica. Gestão da Produção, Operações e Sistemas, v. 3, n. 4, p.11-27, 2008. Disponível em: <http://revista.feb.unesp. br/index.php/gepros/article/viewArticle/501>. Acesso em: 12 out. 2011.

ESWARAMOORTHI, M. et al. A survey on lean practices in Indian machine tool industries. The International Journal of Advanced Manufacturing Technology, v. 52, n. 9-12, p. 1091-1101, 2011. http://dx.doi.org/10.1007/ s00170-010-2788-y

FAZARD, R. S.; MOHAMAD, S.; HOSSEINI, S. New concept in leanness development and assessment in plant life cycle (PLC). International Journal of Engineering Science, v. 19, n. 1, p. 57-65, 2008.

FILIPPINI, R. Operations Management Research: some reflections on evolution, models and empirical studies in OM. International Journal of Operations and Production Management, v. 17, n. 7, p. 655-670, 1997. http://dx.doi.org/10.1108/01443579710175583

FOGARTY, D. W. Work in process: performance measures. International Journal Production Economics, v. 26, n. 1-3, p. 169-172, 1992. http:// dx.doi.org/10.1016/0925-5273(92)90059-G

GOODSON, E. R. Read a plant fast. Harvard Business Review, v. 80, n. 5, p. 105-113, 2002.

GUPTA, S. M.; BRENNAN, L. Implementation of justin-time methodology in a small company. Production Planning and Control, v. 6, n. 4, p. 358-364, 1995. http://dx.doi.org/10.1080/09537289508930290

GURUMURTHY, A.; KODALI, R. Application of benchmarking for assessing the lean manufacturing implementation. Benchmarking: An International Journal, v. 16, n. 2, p. 274-308, 2009.

HAQUE, B.; MOORE, J. M. Measures of performance for lean product introduction in the aerospace industry. Proceedings of the Institution of Mechanical Engineers, Part B: Journal of Engineering Manufacture, v. 218 , n. 10 , p. 1387-1398, 2004. http://dx.doi. org/10.1243/0954405042323496

HOFER, A. R. et al. An institutional theoretic perspective on forces driving adoption of lean production globally China vis- a-vis the USA. The International Journal of Logistics Management, v. 22, n. 2, p. 148-178, 2011. http://dx.doi.org/10.1108/09574091111156532

IM, J. H.; LEE, S. M. Implementation of just-in-time systems in US manufacturing firms. International Journal of Operations and Production Management, v. 9, n. 1, p. 5-14, 1989. http://dx.doi.org/10.1108/ EUM0000000001213

IMAI, M. Kaizen: a estratégia para o sucesso competitivo. 5. ed. São Paulo: IMAM, 1994.

JACKSON, T.; DYER, C. Diagnóstico corporativo: una herramienta para alcanzar la excelencia. Madrid: TGP Hoshin, 1998.

JAIN, V.; BENYOUCEF, L.; DESHMUKH, S. G. A new approach for evaluating agility in supply chains using fuzzy association rules mining. International Journal Engineering Applications of Artificial Intelligence, 
v. 21, n. 3, p. 367-385, 2008. http://dx.doi.org/10.1016/j. engappai.2007.07.004

KARLSSON, C.; AHLSTRÖM, P. Assessing changes towards lean production. International Journal of Operations and Production Management, v. 16, n. 2, p. 21-41, 1996. http://dx.doi.org/10.1108/01443579610109820

KOJIMA, S.; KAPLINSKI, R. The use of a lean production index in explaining the transition to global competitiveness: the auto components sector in South Africa. Technovation, v. 24, n. 3, p. 199-206, 2004.

KUMAR, A.; THOMAS, S. A Software tool for screening analysis of lean practices. Environmental Progress, v. 21, n. 3, p. 12-16, 2002. http://dx.doi.org/10.1002/ ep.670210308

LAGE JÚNIOR, M.; GODINHO FILHO, M. Variations of the kanban system: Literature review and classification. International Journal of Production Economics, v. 125, n. 1, p. 13-21, 2010. http://dx.doi.org/10.1016/j. ijpe.2010.01.009

LEE, Q. Lean Manufacturing Strategy. Kansas City: Strategos, 2011. Disponível em: <www.strategosinc. com>. Acesso em: 03 out. 2011.

LIKER, J. K. O Modelo Toyota: 14 Princípios de Gestão do Maior Fabricante do Mundo. São Paulo: Bookman, 2005.

LUCATO, W. C.; MAESTRELLI, N. C.; VIEIRA JÚNIOR, M. Determinação do Grau de Enxugamento de uma Empresa: uma proposta conceitual. Ciência \& Tecnologia, v. 12, n. 24, p. 25-38, 2006. Disponível em: <http://www.unimep.br/phpg/editora/revistaspdf/ rct24art03.pdf>. Acesso em: 05 nov. 2011.

MARASCO, A. Third-party logistics: a literature review. International Journal Production Economics, v. 113, n. 1, p. 127-147, 2008. http://dx.doi.org/10.1016/j. ijpe.2007.05.017

MATSUI, Y. An empirical analysis of Just-in-time production in japanese manufacturing Companies. International Journal of Production Economics, v. 108, n. 1-2, p. 53-164, 2007. http://dx.doi.org/10.1016/j. ijpe.2006.12.035

MEIRELLES, R. A.; MACHADO, R. N. A funcionalidade e o desempenho do Portal de Periódicos da CAPES entre pesquisadores das áreas de Comunicação e Ciência da Informação da Universidade Federal da Bahia. Perspectivas em Ciências da Informação, v. 12, n. 3, p. 54-64, 2007. http://dx.doi.org/10.1590/ S1413-99362007000300005

MEREDITH, J. Theory building through conceptual methods. International Journal of Operations and Production Management, v. 13, n. 5, p. 3-11, 1993. http://dx.doi.org/10.1108/01443579310028120

MIGUEL, P. A. C. Estudo de caso na engenharia de produção: estruturação e recomendações para sua condução. Produção, v. 17, n. 1, p. 216-229, 2007. http://dx.doi.org/10.1590/S0103-65132007000100015

MORIONES, A. B.; PINTADO, A. B.; CERIO, J. M. D. The role of organizational context and infrastructure practices in JIT implementation. International Journal of Operations and Production Management, v. 28, n. 11, p. 1042-1066, 2008. http://dx.doi. org/10.1108/01443570810910188
NASAB, H. H.; BIOKI, T. A.; ZARE, H. K. Finding a probabilistic approach to analyze lean manufacturing. Journal of Cleaner Production, v. 29-30, p. 73-81, 2012. http://dx.doi.org/10.1016/j.jclepro.2012.02.017

NGAI, E. W. T. et al. RFID research: an academic literature review (1995-2005) and future research directions. International Journal of Production Economics, v. 112, n. 1, p. 510-520, 2008. http://dx.doi.org/10.1016/j. ijpe.2007.05.004

NIGHTINGALE, D. J.; MIZE, J. H. Development of a Lean Enterprise Transformation Maturity Model. Information Knowledge Systems Management, v. 3, n. 1, p. 15-30, 2002.

NOGUEIRA, M. G. S.; SAURIN, T. A. Proposta de avaliação do nível de implementação de típicas práticas da produção enxuta em uma empresa do setor metalmecânico. Produção Online, v. 8, n. 2, 2008. Disponível em: <http://www.producaoonline.org.br/index.php/rpo/ article/view/115>. Acesso em: 03 nov. 2011.

NORONHA, D. P.; FERREIRA, S. M. S. P. Revisões da Literatura. In: CAMPELLO, B. S.; CENDÓN, B. V.; KREMER, J. M. Fontes de Informação para Pesquisadores e Profissionais. Belo Horizonte: UFMG, 2000. p. 191-198.

OHNO, T. O sistema Toyota de produção: Além da produção em larga escala. Porto Alegre: Artes Médicas, 1997.

PAY, R. Everybody's jumping on the lean bandwagon, but many are being taken for a ride. Industry Week, 2008. Disponível em: <http://www.industryweek.com/ ReadArticle.aspx?ArticleID=15881>. Acesso em: 25 jan. 2011.

PAVNASKAR, S. J.; GERSHENSON, J. K.; JAMBEKAR, A. B. Classification scheme for lean manufacturing tools. International Journal of Production Research, v. 41, n. 13 , p. 3075-3090, 2003. http://dx.doi. org/10.1080/0020754021000049817

PUVANASVARAN, P. et al. Lean process management implementation through enhanced problem solving capabilities. Journal of Industrial Engineering and Management, v. 3, n. 3, p. 447-493, 2010. http://dx.doi. org/10.3926/jiem.2010.v3n3.p447-493

RAHMAN, S.; LAOSIRIHONGTHONG, T.; SOHAL, A. S. Impact of lean strategy on operational performance: a study of Thai manufacturing companies. Journal of Manufacturing Technology Management, v. 21, n. 7, p. 839-852, 2010. http://dx.doi. org/10.1108/17410381011077946

RAY, C. D. et al. The lean index: operational "lean" metrics for the wood products industry. Wood and Fiber Science, v. 38, n. 2, p. 238-255, 2006.

RAWABDEH, I. A. A model for the assessment of waste in job shop environments. International Journal of Operations and Production Management, v. 25, n. 8, p. 800-822, 2005. http://dx.doi. org/10.1108/01443570510608619

ROTHER, M.; HARRIS, H. Criando Fluxo Contínuo: Um guia de ação para gerentes, engenheiros e associados da produção. São Paulo: Lean Institute Brasil, 2002. PMCid:113852. 
ROTHER, M.; SHOOK, J. Aprendendo a enxergar: Mapeando o fluxo de valor para agregar valor e eliminar desperdícios. São Paulo: Lean Institute Brasil, 2003.

SÁNCHEZ, M. A.; PÉREZ, M. P. Lean indicators and manufacturing strategies. International Journal of Operations and Production Management, v. 21 , n. 11 , p. 1433-1451, 2001. http://dx.doi. org/10.1108/01443570110407436

SAURIN, T. A.; FERREIRA, C. F. Avaliação qualitativa da implantação de práticas da produção enxuta: estudo de caso em uma fábrica de máquinas agrícolas. Gestão \& Produção, v. 15, n. 3, p. 449-462, 2008. http://dx.doi. org/10.1590/S0104-530X2008000300003

SAURIN, T. A.; MARODIN, G. A.; RIBEIRO, J. L. D. A framework for assessing the use of lean production practices in manufacturing cells. International Journal of Production Research, v. 49, n. 11, p. 3211-3230, 2011. http://dx.doi.org/10.1080/00207543.2010.482567

SELLITTO, M. A.; BORCHARDT, M.; PEREIRA, G. M. Presença dos princípios da mentalidade enxuta e como introduzi-los nas práticas de gestão das empresas de transporte coletivo de Porto Alegre. Produção, v. 20, n. 1, p. 15-29, 2010. http://dx.doi.org/10.1590/ S0103-65132010005000009

SEYEDHOSSEINI, S. M. et al. Extracting leanness criteria by employing the concept of Balanced Scorecard. Expert Systems with Applications, v. 38, n. 8, p. 10454-10461, 2011. http://dx.doi.org/10.1016/j. eswa.2011.02.095

SHAH, R.; WARD, P. T. Lean manufacturing: context, practice bundles and performance. Journal of Operations Management, v. 21, n. 2 p. 129-149, 2003. http://dx.doi. org/10.1016/S0272-6963(02)00108-0

SHAH, R.; WARD, P. T. Defining and developing measures of lean production. Journal of Operations Management, v. 25 , n. 4, p. 785-805, 2007. http://dx.doi.org/10.1016/j. jom.2007.01.019

SHINGO, S. O Sistema Toyota de Produção: Do ponto de vista da Engenharia de Produção. Porto Alegre: Bookman, 1996a. PMid:8905671.

SHINGO, S. Sistemas de produção com estoque zero: o Sistema Shingo para melhorias contínuas. Porto Alegre: Artes Médicas, 1996b. PMid:8905671.

SHINGO, S. Sistema de Troca Rápida de Ferramenta: Uma Revolução nos Sistemas Produtivos. Porto Alegre: Bookman, 2000.

SINGH, B.; GARG, S. K.; SHARMA, S. K. Development of index for measuring leanness: study of an Indian auto component industry. Measuring Business Excellence, v. 14, n. 2, p. 46-53, 2010. http://dx.doi. org/10.1108/13683041011047858

SOCIETY OF AUTOMOTIVE ENGINEERS - SAE. Identification and measurement of best practices for implementing lean operations (SAE standard J4000). SAE, 1999a.

SOCIETY OF AUTOMOTIVE ENGINEERS - SAE. Implementation of lean operations: user manual (SAE standard J4001). SAE, 1999b.

SORIANO-MEIER, H. S.; FORRESTER, P. L. A model for evaluating the degree of leanness of manufacturing firms. Integrated Manufacturing
Systems, v. 13, n. 2, p. 104-109, 2002. http://dx.doi. org/10.1108/09576060210415437

SRINIVASARAGHAVAN, J.; ALLADA, V. Application of Mahalanobis distance as a lean assessment metric. International Journal of Advanced Manufacturing Technology, v. 29, n. 11, p. 1159-68, 2006. http://dx.doi. org/10.1007/s00170-005-0004-2

SWAMIDASS, P. M. The effect of TPS on US manufacturing during 1981-1998: inventory increased or decreased as a function of plant performance. International Journal of Production Research, v. 45, n. 16, p. 3763-3778, 2007. http://dx.doi.org/10.1080/00207540701223675

TAJ, S. Applying lean assessment tools in Chinese hi-tech industries. Management Decision, v. 43, n. 4, p. 628-643, 2005. http://dx.doi. org/10.1108/00251740510593602

TAJ, S. Lean manufacturing performance in China: assessment of 65 manufacturing plants. Journal of Manufacturing Technology Management, v. 19, n. 2, p. 217-234, 2008. http://dx.doi.org/10.1108/17410380810847927

TAJ, S.; MOROSAN, C. The impact of lean operations on the Chinese manufacturing performance. Journal of Manufacturing Technology Management, v. 22, n. 2, p. 223-240, 2011. http://dx.doi. org/10.1108/17410381111102234

TAKAHASHI, Y.; OSADA, T. TPM/MPT: Manutenção Produtiva Total. São Paulo: IMAM, 1993.

TSOURVELOUDI, N. C.; VALAVANIS, K. P. On the measurement of enterprise agility. Journal of Intelligent and Robotic Systems, v. 33, n. 3, p. 329-342, 2002. http://dx.doi.org/10.1023/A:1015096909316

TUBINO, D. F. Planejamento e Controle da Produção: teoria e prática. São Paulo: Atlas, 2007.

UNVER, H. O. An ISA-95-based manufacturing intelligence system in support of lean initiatives. The International Journal of Advanced Manufacturing Technology, 2012. http://dx.doi.org/10.1007/s00170-012-4223-Z

VILLAS, M. V.; SOARES, T. D. L. V. A. M.; RUSSO, G. M. Bibliographical research method for business administration studies: a model based on scientific journal ranking. Brazilian Administration Review, v. 5, n. 2, p. 139-159, 2008.

VINODH, S.; BALAJI, S. R. Fuzzy logic based leanness assessment and its decision support system. International Journal of Production Research, v. 49, n. 13, p. 4027-4041, 2011. http://dx.doi.org/10.1080/00207 543.2010.492408

VINODH, S.; CHINTHA, S. K. Leanness assessment using multigrade fuzzy approach. International Journal of Production Research, v. 49, n. 2, p. 431-44, 2011. http://dx.doi.org/10.1080/00207540903471494

VINODH, S.; PRAKASH, N. H.; SELVAN, K. E. Evaluation of leanness using fuzzy association rules mining. The International Journal of Advanced Manufacturing Technology, v. 57, n. 1-4, p. 343-352, 2011. http:// dx.doi.org/10.1007/s00170-011-3260-3

VINODH, S.; VIMAL, K. E. K. Thirty criteria based leanness assessment using fuzzy logic approach. The International Journal of Advanced Manufacturing Technology, v. 60, n. 9-12, p. 1185-1195, 2012a. http:// dx.doi.org/10.1007/s00170-011-3658-y 
VINODH, S.; VIMAL, K. E. K. Leanness evaluation using IF-THEN rules. International Journal of Advanced Manufacturing Technology, v. 63, n. 1-4, p. 407-413, 2012b.

WAFA, M. A.; YASIN, M. M. A conceptual framework for effective implementation of JIT. International Journal of Operations and Production Management, v. 18, n. 11, p. 1111-1124, 1998. http://dx.doi. org/10.1108/01443579810231697

WAN, H. D.; CHEN, F. F. A leanness measure of manufacturing systems for quantifying impacts of lean initiatives. International Journal of Production Research, v. 46, n. 23, p. 6567-6584, 2008. http://dx.doi. org/10.1080/00207540802230058
WAN, H. D.; CHEN, F. F. Decision support for lean practitioners: A web-based adaptive assessment approach. Computers in Industry, v. 60, n. 4, p. 277-283, 2009. http://dx.doi.org/10.1016/j.compind.2009.01.001

WHITE, R. E.; PEARSON, J. N.; WILSON, J. R. JIT manufacturing: a survey of implementations in small and large U.S. manufacturers. Management Science, v. 45, n. 1, p.1-15, 1999. http://dx.doi.org/10.1287/mnsc.45.1.1

WOMACK, J. P.; JONES, D. T.; ROOS, D. A máquina que mudou o mundo. Rio de Janeiro: Campus, 1992.

WOMACK, J. P.; JONES, D. T. A mentalidade enxuta nas empresas. Rio de Janeiro: Campus, 1992.

ZHOU, B. Lean principles, practices, and impacts: a study on small and medium-sized enterprises (SMEs). Annals of Operation Research, 2012. 


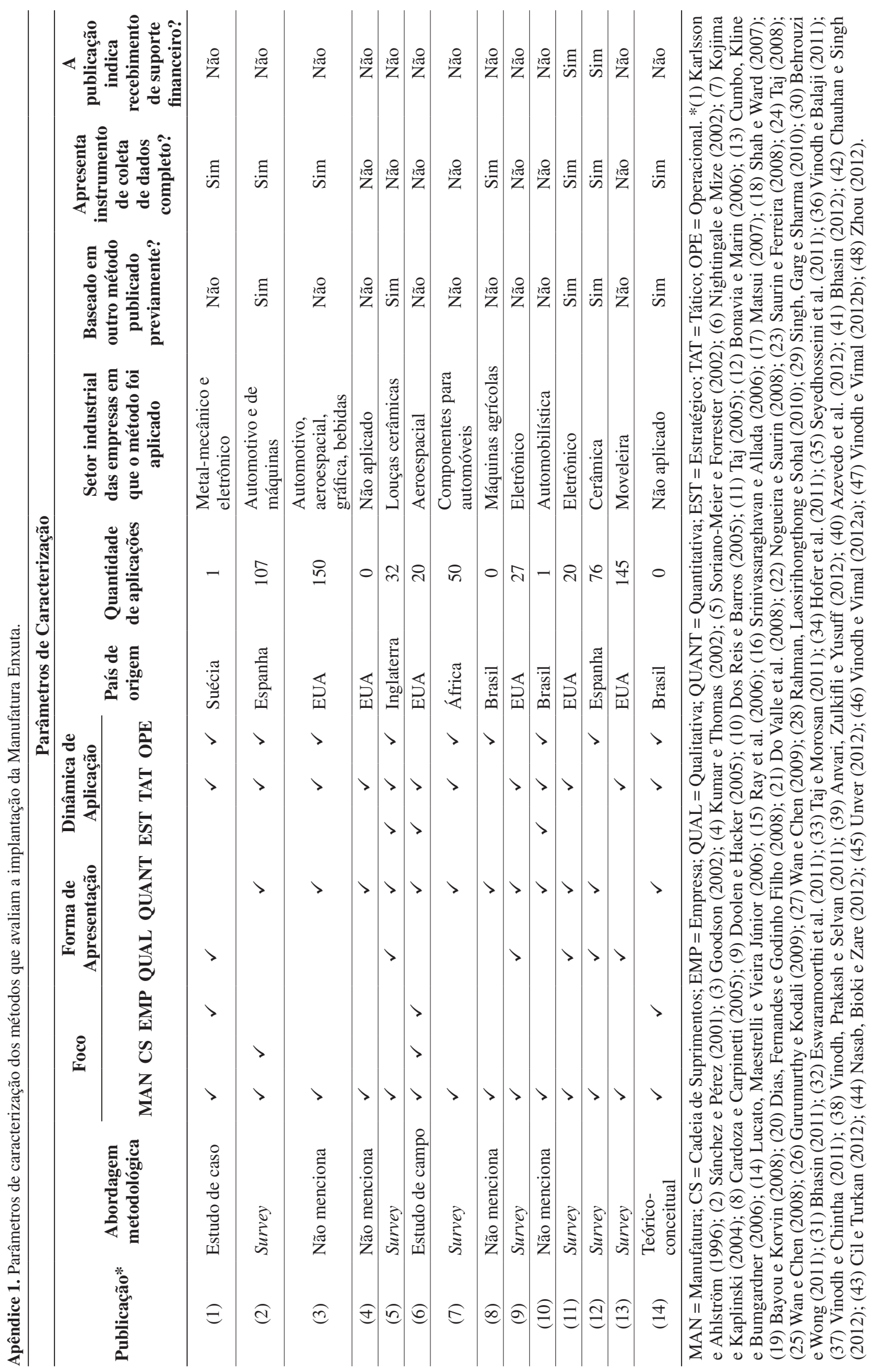




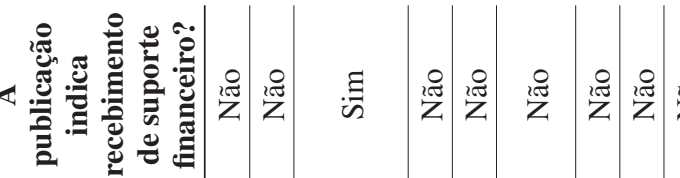

푤

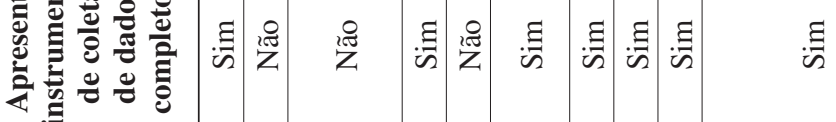

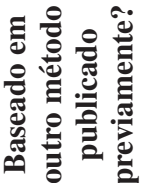

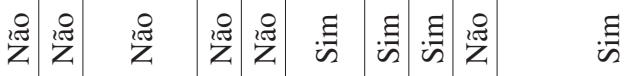

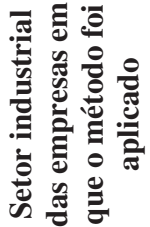

总

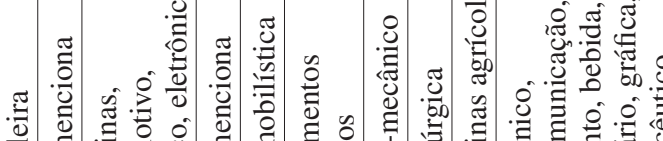

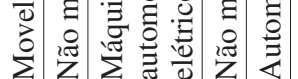

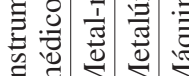

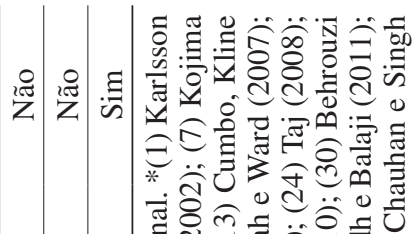

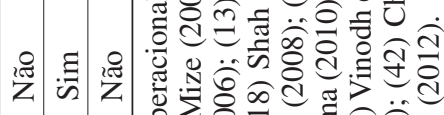

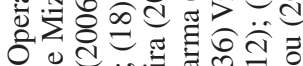
II 0 贻.

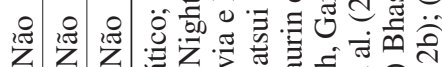

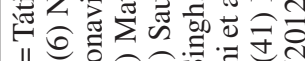

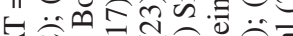

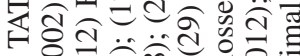

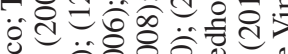

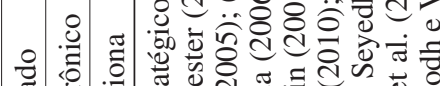
:

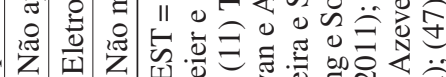

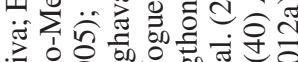

:

¿.

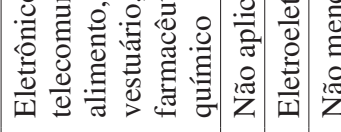

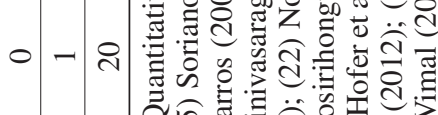
ठ̊ ㅍำ कิ

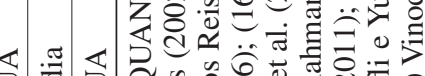

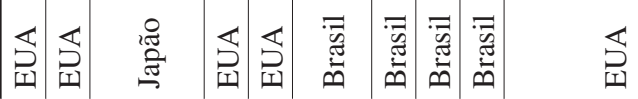

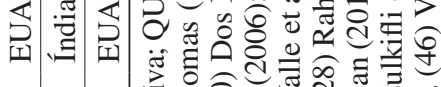

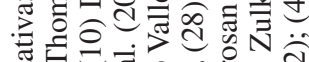
氙

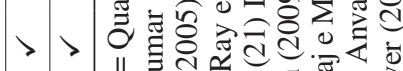

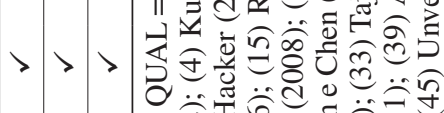

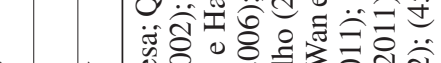

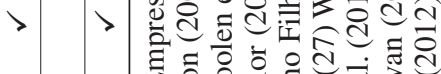

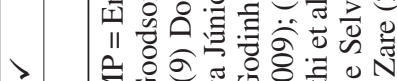

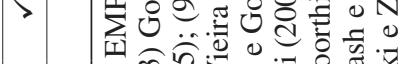

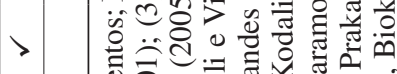
:

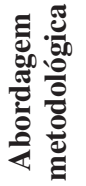

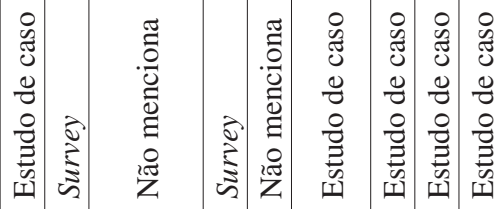

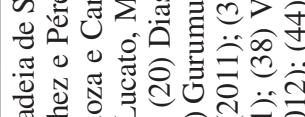
Iี U

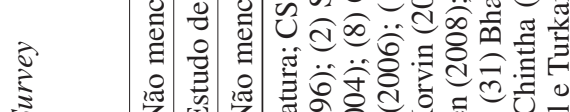
专

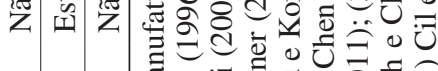

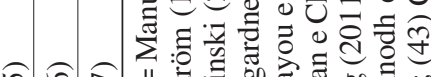

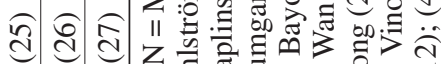

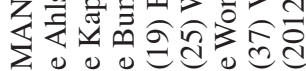




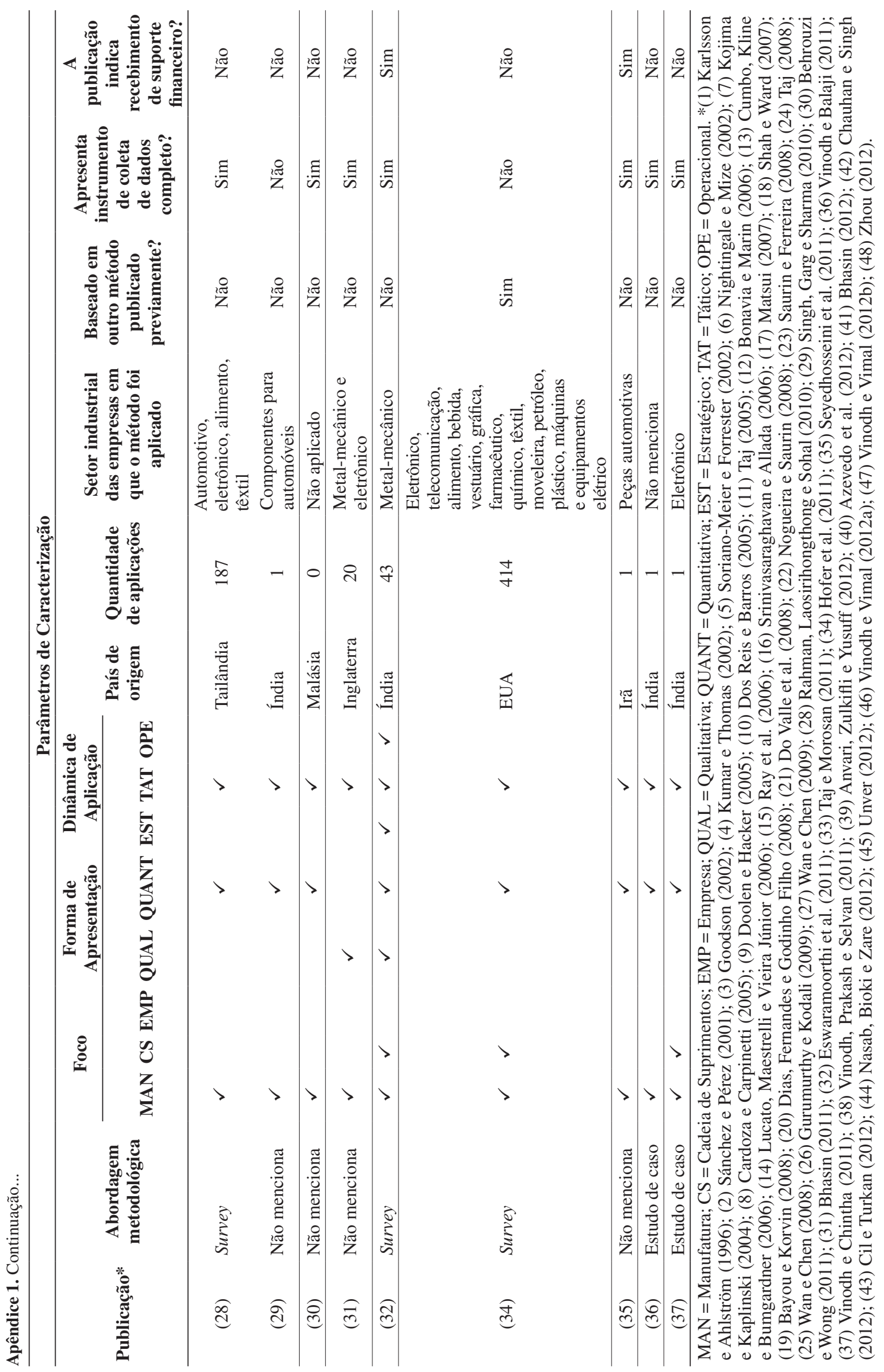




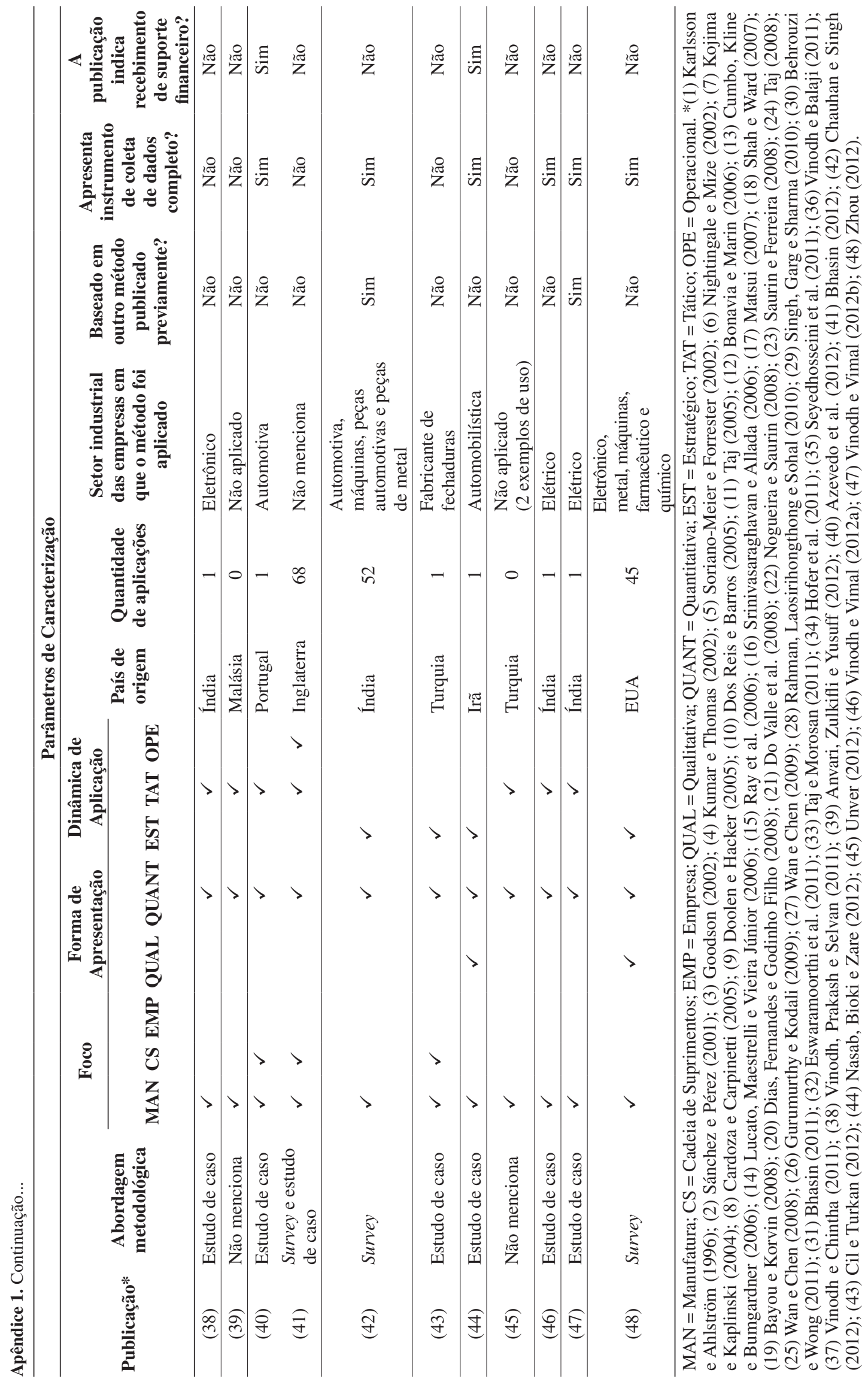




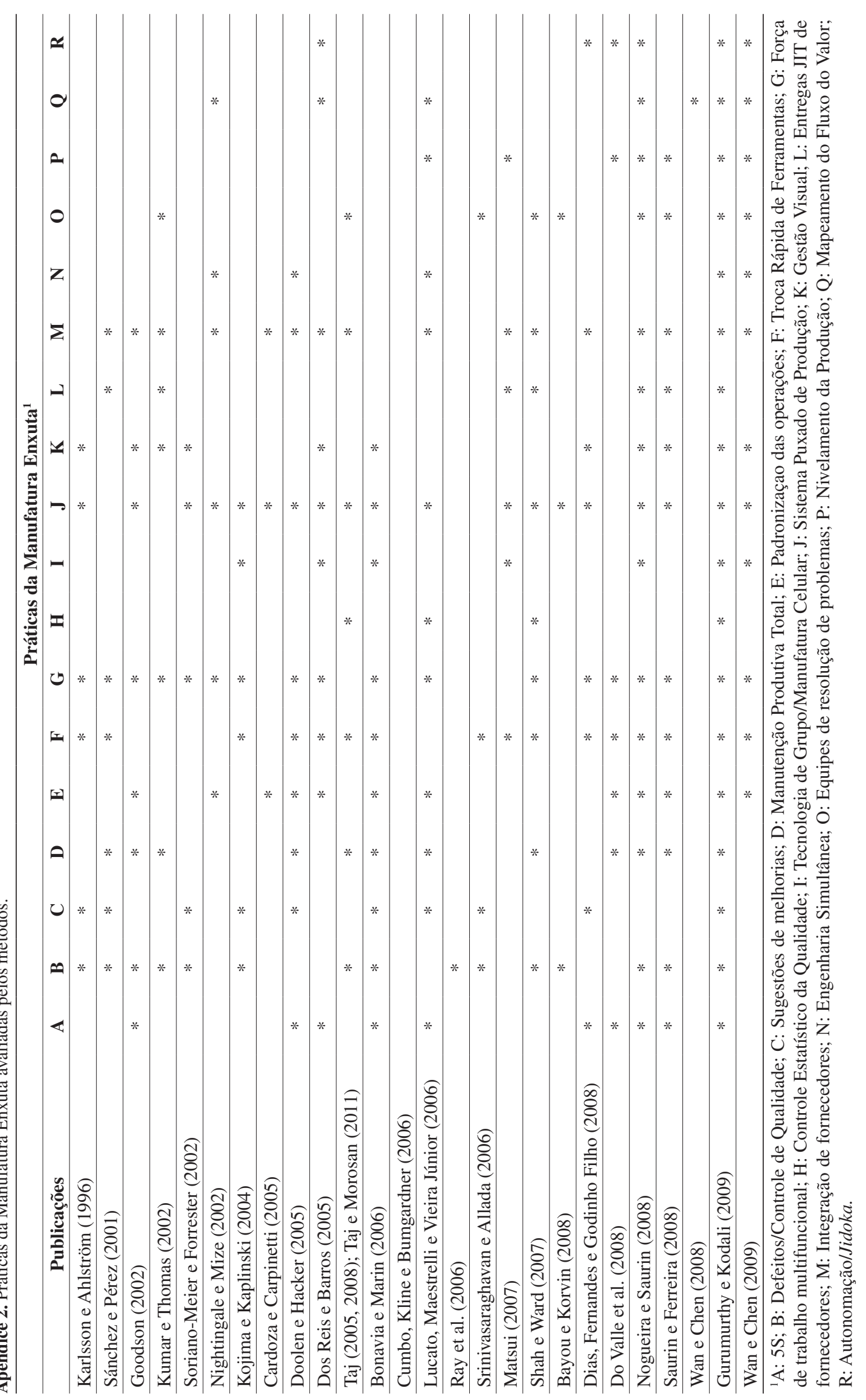




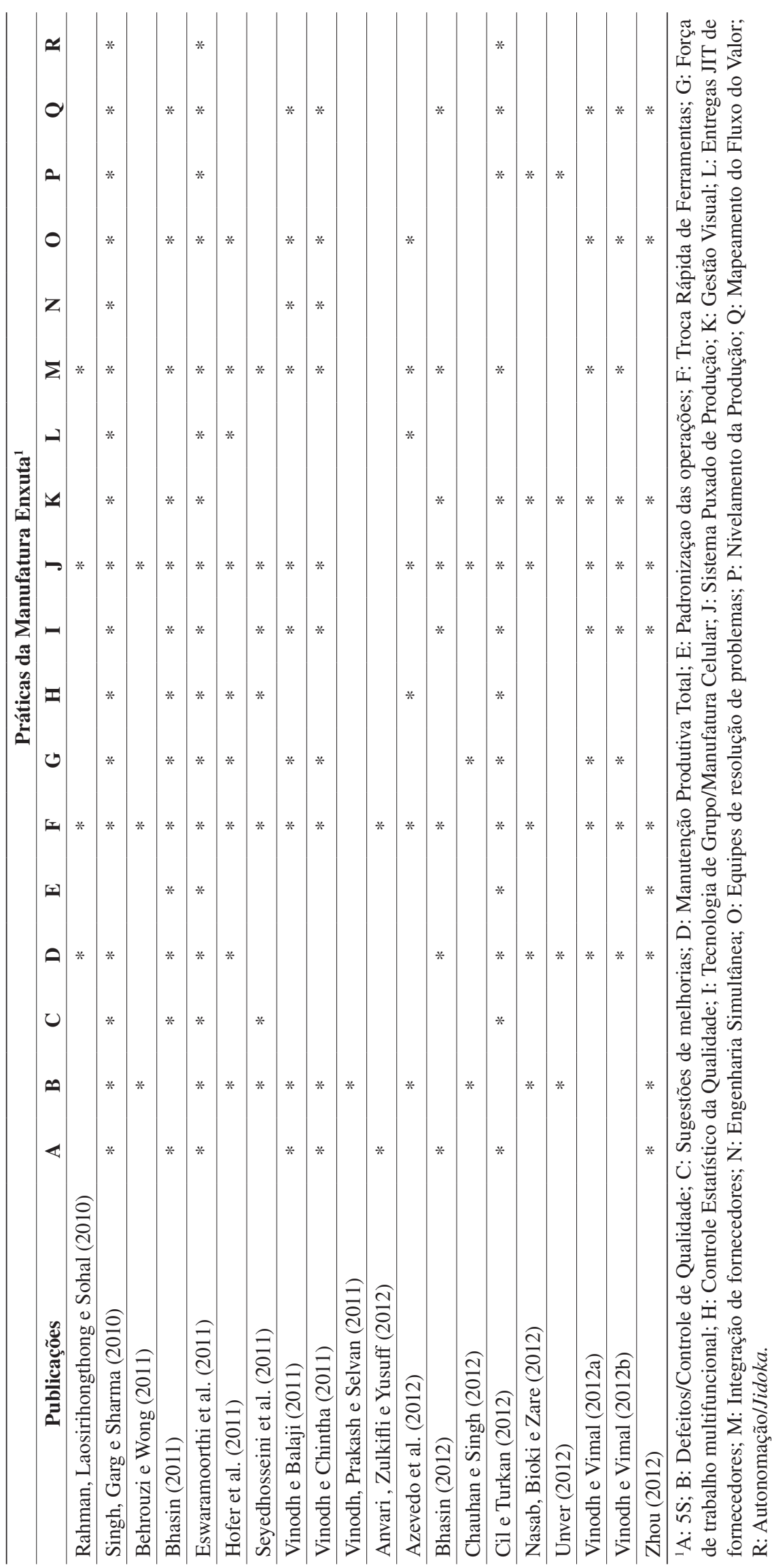

